\title{
Mechanisms linking plant productivity and water status for a temperate Eucalyptus forest flux site: analysis over wet and dry years with a simple model
}

\author{
David A. Pepper ${ }^{\mathrm{A}, \mathrm{E}}$, Ross E. McMurtrie ${ }^{\mathrm{A}}$, Belinda E. Medlyn ${ }^{\mathrm{B}}$, \\ Heather Keith ${ }^{\mathrm{C}}$ and Derek Eamus ${ }^{\mathrm{D}}$ \\ ASchool of Biological, Earth and Environmental Sciences, University of New South Wales, Sydney, \\ NSW 2052, Australia. \\ ${ }^{B}$ Department of Biological Sciences, Macquarie University, North Ryde, NSW 2109, Australia. \\ ${ }^{\mathrm{C}}$ The Fenner School of Environment and Society, Australian National University, Canberra, ACT 0200, Australia. \\ DInstitute for Water and Environmental Resource Management and Department of Environmental Sciences, \\ University of Technology, Sydney, NSW 2007, Australia. \\ ${ }^{\mathrm{E}}$ Corresponding author. Email: d.a.pepper@unsw.edu.au
}

This paper originates from a presentation at EcoFIZZ 2007, Richmond, New South Wales, Australia, September 2007.

\begin{abstract}
A simple process-based model was applied to a tall Eucalyptus forest site over consecutive wet and dry years to examine the importance of different mechanisms linking productivity and water availability. Measured soil moisture, gas flux $\left(\mathrm{CO}_{2}, \mathrm{H}_{2} \mathrm{O}\right)$ and meteorological records for the site were used. Similar levels of simulated $\mathrm{H}_{2} \mathrm{O}$ flux in 'wet' and 'dry' years were achieved when water availability was not confined to the first $1.20 \mathrm{~m}$ of the soil profile, but was allowed to exceed it. Although the simulated effects of low soil and atmospheric water content on $\mathrm{CO}_{2}$ flux, presumably via reduction in stomatal aperture, also acted on transpiration, they were offset in the dry year by a higher vapour-pressure deficit. A sensitivity analysis identified the processes that were important in wet versus dry years, and on an intra-annual timeframe. Light-limited productivity dominated in both years, except for the driest period in the dry year. Vapour-pressure deficit affected productivity across more of each year than soil moisture, but both effects were larger in the dry year. The introduction of a reduced leaf area tended to decrease sensitivity in the dry year. Plant hydraulic architecture that increases plant available water, maximises productivity per unit water use and achieves lower sensitivity to low soil moisture levels should minimise production losses during dry conditions.
\end{abstract}

Additional keywords: $\mathrm{CO}_{2}$ flux, drought, evapotranspiration, water flux, water use.

\section{Introduction}

The pattern of precipitation in Australia has changed considerably over the past three decades (Lavery et al. 1997) and is forecast to change further in the future (Pittock 2003; CSIRO and Australian Bureau of Meteorology 2007). In south-eastern Australia, the drought frequency and potential evaporation rate are predicted to increase, and annual average rainfall is predicted to decrease by $7.5-10 \%$ relative to the 1990 level by the year 2070 (CSIRO and Australian Bureau of Meteorology 2007). Water availability is a strong determinant of growth in Australian forests, which are dominated by evergreen and broadleaved tree species (Fitzpatrick and Nix 1970), unlike many forest sites studied in the northern hemisphere (e.g. Hughes 2003). Understanding the mechanisms linking Australian forest productivity and site water status will enhance our capacity to manage forest and other natural resources (Ladiges 1974; Davidson and Reid 1989; Oren et al. 1999) for a future with less reliable rainfall, and this understanding is important for predicting the effects of environmental change on water budgets and carbon sequestration (Zhang et al. 2001, 2004; Eamus 2003).

In this paper we describe a modelling analysis of a tall, cool temperate Eucalyptus forest using records of soil moisture and eddy-covariance flux measurements of water vapour and $\mathrm{CO}_{2}$ taken at the Tumbarumba flux station (Leuning et al. 2005). This flux site is situated within the Bago State Forest, which is located in the highlands of south-eastern New South Wales, Australia, and receives a moderate level of annual precipitation that has fluctuated over the past several decades by approximately $\pm 20 \%$. The site has undergone other empirical (Leuning et al. 2005) and modelling analyses (Kirschbaum et al. 2007) that complement our study, but which differ considerably in model structure and approach. Our strategy (cf. Kirschbaum et al. 2007) is to apply a simple ecosystem model (Dewar 1997) to the Eucalyptus forest at the Tumbarumba flux site and to focus on the effects of variation 
in soil and atmospheric moisture content on productivity using measurements of soil water together with $\mathrm{CO}_{2}$ and water-vapour fluxes taken in consecutive 'wet' and 'dry' years. The model integrates small-scale, process-level phenomena into a description of ecosystem function (e.g. Hanson et al. 2004). The relatively simple process-based model of daily light use, carbon dynamics and their interaction with site water availability provides a mechanistic framework to apply to the forest ecosystem, and to use with UNCSIM software procedures (Brun et al. 2001) to evaluate the importance of ecosystem processes under variable environmental conditions. Nutrient cycling has been omitted from the model to focus solely on the effects of soil and atmospheric water content on productivity over a relatively short term with respect to net changes in the nutrient balance in the Bago State Forest. Simulated forest light use and therefore net primary production is negatively impacted by both a dry atmosphere and a dry soil (e.g. Schulze et al. 1994; Ciais et al. 2005). Both agreement and discrepancy between the simulated output and their corresponding measurements have been used to improve our understanding of key mechanisms at work in wet versus dry years for this particular system. Therefore, our approach uses the model framework as a probe into the system rather than as a test of the predictive capacity of the model.

Leuning et al. (2005) concluded that $\mathrm{CO}_{2}$ fluxes at the Tumbarumba flux site are more strongly constrained by available water than by temperature because net negative monthly $\mathrm{CO}_{2}$ fluxes (net $\mathrm{CO}_{2}$ uptake by the forest) were lowest during the dry autumn (April 2003), when mean air temperature $\left(\mathrm{T}_{\mathrm{a}}\right)$ was $8.0^{\circ} \mathrm{C}$ and soil moisture stored in the top $1.20 \mathrm{~m}$ fell to $260 \mathrm{~mm}$, compared with the wet, cold winter (August 2001), when mean $\mathrm{T}_{\mathrm{a}}$ fell to $0.2^{\circ} \mathrm{C}$ and stored soil moisture was greater than $350 \mathrm{~mm}$. However, Leuning et al. (2005) noted that the forest was able to maintain transpiration during the dry summer of 2002-2003 and suggested that this occurred because tree roots had access to water stored deep $(>3 \mathrm{~m})$ in the soil (McKenzie and Ryan 1999). Leuning et al. (2005) found that night-time $\mathrm{CO}_{2}$ efflux from the forest was strongly related to soil temperature, but not to soil moisture. The modelling analysis described below will seek a mechanistic understanding of lower annual $\mathrm{CO}_{2}$ uptake in the dry year compared with that in the wet year, even though annual water flux was similar in the 2 years (Fig. 1).

The present study has two main aims. The first aim is to use a simple model framework to improve our understanding of carbon and water dynamics in a tall Eucalyptus forest over wet and dry years. Using the model framework we wanted to assess whether there were any moisture-related effects on productivity (e.g. Eamus 2003; Rascher et al. 2004; Whitehead and Beadle 2004) at this site or whether these effects were negligible because of access to deep water sources (e.g. Meinzer et al. 1999; Leuning et al. 2005). For this aim, we take a strategic approach to model parameterisation. Thus, we investigate the relative impacts of variation in soil and atmospheric moisture content on carbon dynamics, and determine whether the model successfully fits daily measurements of multiple forest variables. The second aim is to identify which processes in the model differ between wet and dry years, and when they become important on an intra-annual timeframe, by using the calibrated model to undertake a sensitivity analysis of the key parameters. This approach uses parameters in the model related to mechanisms linking productivity and site water status (Calder 1992; Honeysett et al. 1992, 1996; Eamus 2003; Rascher et al. 2004; Whitehead and Beadle 2004). These mechanisms include: stomatal responses to vapour-pressure deficit and soil water (Pereira et al. 1987; White et al. 1996; Thomas and Eamus 1999); hydraulic conductance (White et al. 1998; Eamus et al. 2001); biomass allocation to roots and leaves (e.g. Li and Wang 2003); variations in canopy leaf area and/or specific leaf area (Whitehead and Beadle 2004); and variations in respiration (Turnbull et al. 2001).

\section{Materials and methods}

\section{Site description and measurements}

The Tumbarumba site $\left(35^{\circ} 39^{\prime} \mathrm{S}, 148^{\circ} 09^{\prime} \mathrm{E}\right.$; elevation $1200 \mathrm{~m}$ a.s.1.) is located within the Bago State Forest in south-eastern New South Wales, Australia. The Bago State Forest is part of a 50000 ha native forest that has been managed for wood production for over 100 years. The site is a moderately open, wet sclerophyll forest composed of mixed-aged trees ranging up to 90 years and $40 \mathrm{~m}$ tall. The overstorey is dominated by Eucalyptus delegatensis R.T. Baker and Eucalyptus dalrymplean Maiden tree species, and has a leaf area index (LAI) of $\sim 1.4$. The understorey comprises shrubs and grasses with an estimated LAI of $\sim 1.0$ (Leuning et al. 2005). The soil is $\sim 2 \mathrm{~m}$ deep, classified as an acidic, eutrophic, red dermosol, overlays a weathered $\mathrm{C}$ horizon (H. Keith, unpubl. data), and has moderate levels of stored carbon and nutrients (McKenzie and Ryan 1999).

Mean annual precipitation (1 July-30 June) for the period 1887-2007, recorded at Tumbarumba Post Office, which is located $40 \mathrm{~km}$ south of the site, was $978 \pm 204 \mathrm{~mm}$ (mean \pm s.d.). From mid-winter 2001 to mid-winter 2002 the precipitation measured at the study site was $1090 \mathrm{~mm}$ ('wet' year), but in the following year the precipitation was $\sim 20 \%$ below average ( $785 \mathrm{~mm}$; 'dry' year), owing mainly to an extended dry period from October 2002 to April 2003 (from approximately day 640 to 850 in Fig. 1). The average $T_{a}$ ranged from 0 to $18^{\circ} \mathrm{C}$ and the daytime humidity deficit ranged from 1.5 to $16.4 \mathrm{mmol} \mathrm{mol}^{-1}$, and both were higher in the dry year (July 2002-June 2003).

Fluxes of water vapour and $\mathrm{CO}_{2}$ were measured and logged hourly (Leuning et al. 2005). Soil moisture content was measured using time domain reflectometry (Zegelin and White 1989 ) at $0.15-\mathrm{m}$ depth intervals from the surface to $1.20 \mathrm{~m}$ and logged hourly. Full details of the instrumentation, flux-data processing and soil moisture measurements are provided by Leuning et al. (2005) and references therein. The hourly soil moisture and flux data were used in the present study to derive daily and daytime totals that corresponded to outputs from our daily time-step model. Some litterfall data have been collected for the site (H. Keith, unpubl. data, Kirschbaum et al. 2007), and these were used to add variation in LAI for use in the sensitivity analysis.

\section{Model description}

The model of light and water use simulates daily carbon and water balance. A light-use efficiency approach is used to simulate 

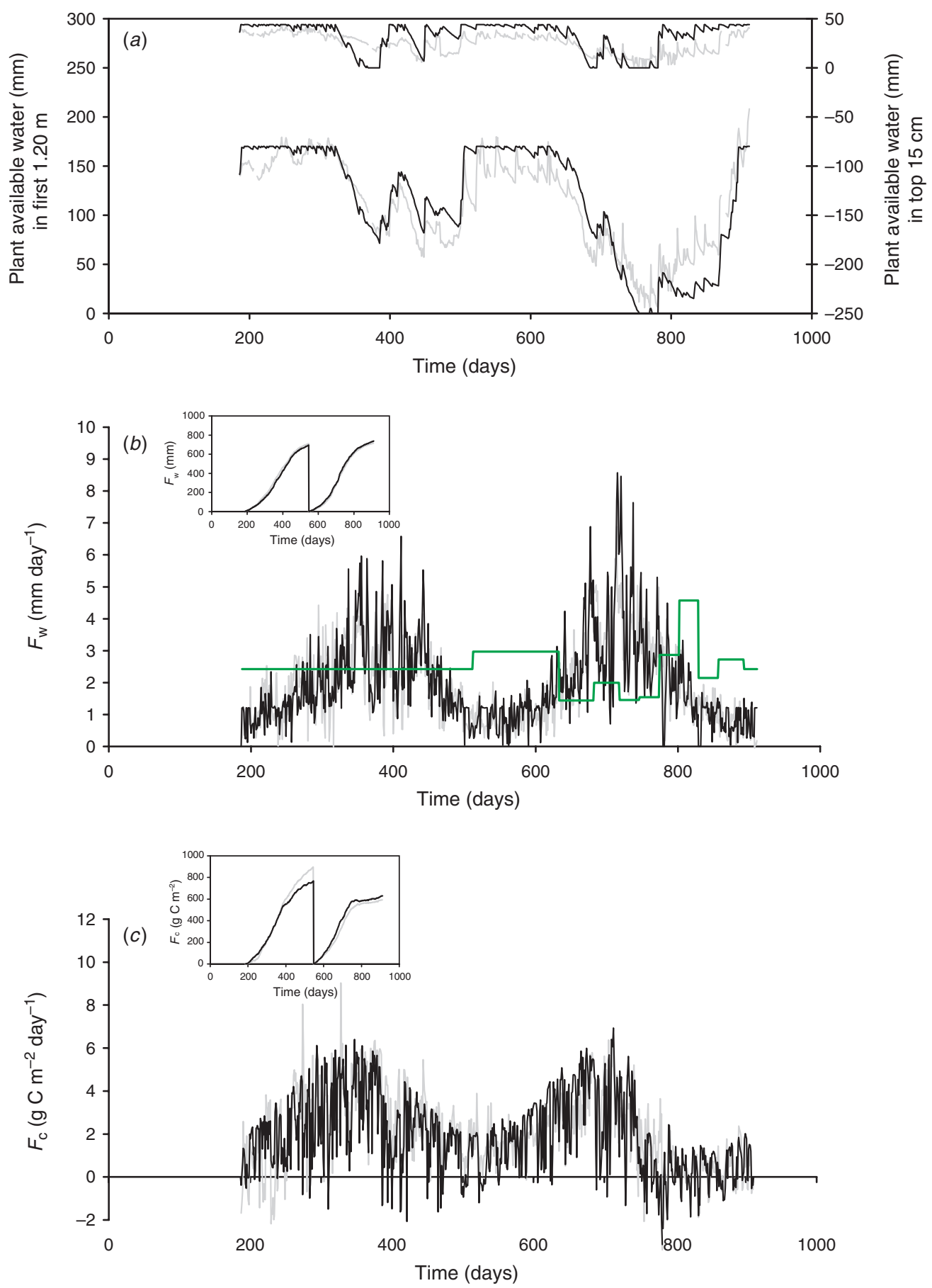

Fig. 1. Measured (grey line) and simulated (black line) variables at the Tumbarumba, NSW, Australia, flux site over wet and dry years. (a) Plant-available water in the $0-0.15 \mathrm{~m}$ (upper) and $0-1.20 \mathrm{~m}$ (lower) soil layers; $(b)$ water vapour flux $\left(F_{\mathrm{w}}\right)$ and variable leaf area index (LAI) (inset is the cumulative $F_{\mathrm{w}}$ ); and $(c) \mathrm{CO}_{2}$ flux $\left(F_{\mathrm{c}}\right)$ (inset is the cumulative $F_{\mathrm{c}}$ ). Day 1 corresponds to 1 January 2001.

productivity. Transpiration and productivity are related by wateruse efficiency. The effects of soil moisture and vapour-pressure deficit on carbon productivity and transpiration are represented using relatively simple functions that act to reduce light-use efficiency. Temperature effects act to increase light-use efficiency. Surface evaporation from the soil and the canopy are also incorporated into the water flux calculation. Model inputs include daily meteorological data collected for the site: total solar radiation (TSR; $\mathrm{MJ} \mathrm{m}^{-2} \mathrm{day}^{-1}$ ), maximum and minimum air temperature $\left(\mathrm{T}_{\max }\right.$ and $\mathrm{T}_{\min }$, respectively; $\left.{ }^{\circ} \mathrm{C}\right)$, daytime average vapour-pressure deficit $(\mathrm{D} ; \mathrm{kPa})$, precipitation $(P ; \mathrm{mm})$, and average soil temperature at a depth of $2 \mathrm{~cm}\left(\mathrm{~T}_{\mathrm{s}} ;{ }^{\circ} \mathrm{C}\right)$. The 
model outputs include daily $\mathrm{CO}_{2}$ flux, water flux and soil moisture storage in the $0-0.15 \mathrm{~m}$ and $0-1.20 \mathrm{~m}$ layers of soil. Definitions for all symbols are listed in Table 1.

\section{Carbon balance}

Daily $\mathrm{CO}_{2}$ flux $\left(F_{\mathrm{c}} ; \mathrm{g} \mathrm{C} \mathrm{m}^{-2}\right.$ day $\left.^{-1}\right)$ is modelled as the difference between gross primary productivity (GPP) and ecosystem respiration (RE),

$$
F_{\mathrm{c}}=\mathrm{GPP}-\mathrm{RE},
$$

where GPP is approximated as net primary productivity divided by carbon-use efficiency (CUE) $(\mathrm{GPP}=\mathrm{NPP} / \mathrm{CUE})$, where it is assumed that autotrophic respiration is a constant fraction of GPP (e.g. Gifford 1992, 2003; Waring et al. 1998; Dewar et al. 1999), and RE is simulated with a site-derived function depending on soil temperature, but not soil moisture (Leuning et al. 2005),

$$
\mathrm{RE}=a \mathrm{e}^{b \mathrm{Ts}}
$$

where $a=0.46 \mu \mathrm{mol} \mathrm{CO}_{2} \mathrm{~m}^{-2} \mathrm{~s}^{-1}$ and $b=0.132^{\circ} \mathrm{C}^{-1}$, and $\mathrm{RE}$ in units of $\mu \mathrm{mol} \mathrm{CO}_{2} \mathrm{~m}^{-2} \mathrm{~s}^{-1}$ was converted to $\mathrm{g} \mathrm{C} \mathrm{m}^{-2}$ day ${ }^{-1}$. The RE simulated by Eqn 2 is considerably lower than that estimated by van Gorsel et al. (2007). Further analysis of $\mathrm{CO}_{2}$ flux is currently in progress, particularly in relation to representing processes that determine the net difference between GPP and RE. Although the use of Eqn 2 will have a qualitative effect on the results of the sensitivity analysis it will have a negligible effect on the comparison between wet and dry years. Our modelling analysis is based on the RE estimates of Leuning et al. (2005) (Eqn 2).

Net primary productivity is assumed to be proportional to the absorbed photosynthetically active radiation (APAR; $\mathrm{MJ} \mathrm{m}^{-2}$ day $^{-1}$ ), with three modifying functions, $f_{\mathrm{D}}, f_{\mathrm{W}}$ and $f_{\mathrm{T}}$, representing the effects of relative atmospheric water vapourpressure deficit, soil water content and temperature on NPP, respectively.

$$
\mathrm{NPP}=\varepsilon \operatorname{APAR} f_{\mathrm{D}} f_{\mathrm{W}} f_{\mathrm{T}},
$$

where $\varepsilon$ represents the maximum light-use efficiency $\left(\mathrm{g} \mathrm{DW} \mathrm{MJ}^{-1}\right)$; we held the carbon fraction of the dry weight biomass constant $\left(0.48 \mathrm{~g} \mathrm{C} \mathrm{g} \mathrm{DW}^{-1}\right)$. APAR depends on LAI and incident radiation $\left(\mathrm{PAR}_{0}\right)$ in a Beer's Law formulation simulating light extinction through the canopy,

$$
\operatorname{APAR}=\operatorname{PAR}_{0}\left(1-\mathrm{e}^{-k \mathrm{LAI}}\right),
$$

where $k$ is the light-extinction coefficient. The vapour-pressure deficit modifier $f_{\mathrm{D}}$ decreases linearly from 1 to 0 as the vapourpressure deficit increases from a minimum point $\left(D_{\min }\right)$, at which $\mathrm{D}$ begins to affect NPP, to a maximum point $\left(D_{\max }\right)$ when $f_{\mathrm{D}}$ reaches zero,

$$
\begin{aligned}
f_{\mathrm{D}} & =\left(D_{\max }-\mathrm{D}\right) /\left(D_{\max }-D_{\min }\right) \text { if } D_{\min }<\mathrm{D}<D_{\max } \\
& =1 \quad \text { if } \quad \mathrm{D} \leq D_{\min } \\
& =0 \quad \text { if } \quad \mathrm{D} \geq D_{\max } .
\end{aligned}
$$

For example, if $D_{\max }=4 \mathrm{kPa}$ and $D_{\min }=1 \mathrm{kPa}$, then as D increases from $0 \mathrm{kPa}, f_{\mathrm{D}}$ plateaus at 1 and then decreases to 0 (at $\mathrm{D}=4 \mathrm{kPa}$ ) and then plateaus at $0 ; f_{\mathrm{D}}$ fluctuates with changes in
$\mathrm{D}$ between 1 and $4 \mathrm{kPa}$ ( $\mathrm{D}$ in the present study is $<4 \mathrm{kPa}$ ). The $f_{\mathrm{D}}$ attempts to simulate stomatal closure in response to $\mathrm{D}$, and accounts for days when D is high and transpiration is fast, leading to a reduction in stomatal conductance even when soil moisture levels are not low.

Soil-water-limited NPP is simulated through the soil-water factor, $f_{\mathrm{W}}$, which is represented by a ramp function similar to that in Corbeels et al. (2005),

$$
\begin{gathered}
f_{\mathrm{W}}=\left(Q / Q_{\max }-F_{\mathrm{wpmin}}\right) /\left(F_{\mathrm{wpmax}}-F_{\mathrm{wpmin}}\right) \\
\quad \text { if } 0 \leq Q / Q_{\max }<F_{\mathrm{wpmax}} \\
=1 \quad \text { if } \quad Q / Q_{\max } \geq F_{\mathrm{wpmax}}
\end{gathered}
$$

where $F_{\text {wpmax }}$ is the critical fraction of maximum plant-available water capacity $Q_{\max }$ below which plant-available water $Q$ affects NPP. Plant available water is equivalent to the soil moisture fraction between the soil moisture levels at wilting point and maximum field capacity. The temperature factor $f_{\mathrm{T}}$ was simulated with an empirical function associating biological activity with temperature (e.g. Parton et al. 1987; Comins and McMurtrie 1993; Eliasson et al. 2005),

$$
f_{\mathrm{T}}=\mathrm{a}+b \mathrm{~T}^{\mathrm{c}}-(\mathrm{T} / d)^{\mathrm{e}},
$$

where $a=1, b=0.00251, c=1.65, d=41.75$ and $e=7.19$ so that $f_{\mathrm{T}}$ scaled between 1 and 1.62 (at $33^{\circ} \mathrm{C}$ ). Incorporation of $f_{\mathrm{T}}$ acknowledges that the temperature effects on productivity are independent of the temperature effects on respiration in Eqn 1.

\section{Water balance}

Soil water balance was simulated on a daily basis. A simple soil water balance model calculates water storage in the soil root zone. Soil water storage capacity in the root zone is represented as a fixed 'bucket' volume, with provision for $0-0.15 \mathrm{~m}, 0-1.20 \mathrm{~m}$ and a deeper layer. Soil water level in the top layer $(0-0.15 \mathrm{~m})$ affects evaporation from the soil surface $(E)$. Soil water level in the total bucket affects drainage $(D)$ and transpiration $(T)$. The daily change in plant available soil water level $(\Delta Q ; \mathrm{mm})$ is calculated as,

$$
\Delta Q=P-I-E-T-D,
$$

where $P, I, E, T$ and $D$ represent daily values of precipitation, canopy interception loss, evaporation from the soil surface, transpiration and drainage, respectively. Water loss from canopy interception $(I)$ is simulated as (McMurtrie et al. 1990):

$$
I=\min \left(I_{\max }, P\right),
$$

where

$$
I_{\max }=z \mathrm{LAI},
$$

and $z$ is a proportionality constant. Evaporation from the soil surface is driven by incident solar radiation, but is limited by the available water in the top soil layer. The available energy for soil water evaporation is related to the fraction of net radiation reaching the forest floor,

$$
E=R_{\mathrm{N}} \mathrm{e}^{-r \mathrm{LAI}}(e / \lambda(1+e)) f_{\mathrm{Wtop}}
$$

where $r$ is an energy extinction coefficient from Ritchie (1972) and $\lambda$ is the latent heat of vaporisation $\left(2.47 \mathrm{MJ} \mathrm{kg}^{-1}\right)$ from 
Table 1. Model symbols and their descriptions

\begin{tabular}{|c|c|c|c|}
\hline Symbol & Units & Description & Value \\
\hline$a, b$ & $\ldots$ & Coefficients in Eqn 2 & $0.46,0.132$ \\
\hline albedo & $\ldots$ & Reflection coefficient for solar radiation of natural surfaces & 0.2 \\
\hline APAR & $\mathrm{MJ} \mathrm{m}^{-2}$ day $^{-1}$ & Photosynthetically active radiation absorbed by the canopy & \\
\hline CUE & $\ldots$ & Carbon-use efficiency & 0.5 \\
\hline$c$ & $\ldots$ & Constant in $\mathrm{s} / \gamma$ equation (Eqn 14$)$ & 250300 \\
\hline $\mathrm{D}$ & $\mathrm{KPa}(1 \mathrm{kPa}=10 \mathrm{mb})$ & Daytime vapour-pressure deficit & Input \\
\hline$d$ & $\ldots$ & Constant in $\mathrm{s} / \gamma$ equation (Eqn 14$)$ & 17.269 \\
\hline$D_{\max }, D_{\min }$ & $\mathrm{kPa}$ & Maximum and minimum parameters in Eqn 5 & $7.45,1.0$ \\
\hline$E$ & $\mathrm{~mm} \mathrm{day}^{-1}$ & Soil evaporation & \\
\hline$e$ & $\ldots$ & $\mathrm{s} / \gamma($ Eqn 14$)$ & \\
\hline$f 1, f 2$ & & $\begin{array}{l}\text { Fraction of transpiration extracted from } 0-0.15 \mathrm{~m} \\
\text { and } 0-1.20 \mathrm{~m} \text { soil layers }\end{array}$ & $0.1,0.5$ \\
\hline$F_{\mathrm{c}}$ & $\mathrm{g} \mathrm{C} \mathrm{m}^{-2} \mathrm{day}^{-1}$ & $\mathrm{CO}_{2}$ flux & Output \\
\hline$f_{\mathrm{D}}$ & $\cdots$ & $\begin{array}{l}\text { Vapour-pressure deficit multiplier of net primary } \\
\text { productivity }\end{array}$ & \\
\hline$f_{\mathrm{w}}$ & $\ldots$ & Soil water multiplier of net primary productivity & \\
\hline$F_{\mathrm{w}}$ & $\mathrm{mm}_{\mathrm{day}}{ }^{-1}$ & Water flux & Output \\
\hline$F_{\text {wpmax }}$ & $\ldots$ & Fraction of $Q_{\max }$ below which $f_{\mathrm{w}}<1$ & 0.3 \\
\hline$F_{\text {wpmin }}$ & $\ldots$ & Adjusts slope of $f_{\mathrm{w}} v \cdot Q$ & -0.5 \\
\hline$f_{\text {Wtop }}$ & $\ldots$ & Soil water multiplier of soil evaporation from the top layer & \\
\hline GPP & $\mathrm{gC} \mathrm{m}^{-2}$ day $^{-1}$ & Gross primary productivity & \\
\hline$h$ & $\ldots$ & Constant in $\mathrm{s} / \gamma$ equation (Eqn 14$)$ & 6.46 \\
\hline$I$ & $\mathrm{~mm}_{\text {day }}{ }^{-1}$ & Canopy interception & \\
\hline$k$ & $\ldots$ & Light-extinction coefficient & 0.5 \\
\hline$m$ & $\ldots$ & Constant in $R_{\mathrm{L}}$ equation (Eqn 12) & 0.0036 \\
\hline$n$ & $\ldots$ & No. differences calculated for each drying cycle (Table 2) & \\
\hline NPP & $\mathrm{gC} \mathrm{m}^{-2}$ day $^{-1}$ & Net primary productivity & Output \\
\hline$P$ & $\mathrm{~mm} \mathrm{day}^{-1}$ & Precipitation & Input \\
\hline$p$ & $\ldots$ & Constant in $R_{\mathrm{L}}$ equation (Eqn 12) & 12 \\
\hline PAR & $\mathrm{MJm}^{-2}$ day $^{-1}$ & Photosynthetically active radiation & \\
\hline $\mathrm{PAR}_{0}$ & $\mathrm{MJ} \mathrm{m}^{-2}$ day $^{-1}$ & Incident photosynthetically active radiation & Input \\
\hline$q$ & $\ldots$ & Constant in $R_{\mathrm{L}}$ equation (Eqn 12) & 107 \\
\hline$Q, Q 1, Q 2$ & $\mathrm{~mm}$ & $\begin{array}{l}\text { Plant-available water in the root zone, top } 0-015 \mathrm{~m} \text { layer } \\
\text { and } 0-1.20 \mathrm{~m} \text { layer }\end{array}$ & Output \\
\hline$q_{0}$ & $\mathrm{~g} \mathrm{C} \mathrm{kPa} \mathrm{m}^{-2} \mathrm{~mm}^{-1}$ & Intrinsic water-use efficiency & 1.8 \\
\hline$Q 1, Q 1_{\max }$ & $\mathrm{mm}$ & Plant-available water in the $0-0.15 \mathrm{~m}$ soil layer, maximum & Output, 44.1 \\
\hline$Q 2, Q 2_{\max }$ & $\mathrm{mm}$ & Plant-available water in the $0-1.20 \mathrm{~m}$ soil layer, maximum & Output, 170 \\
\hline$Q_{\max }$ & $\mathrm{mm}$ & Maximum plant-available water & 350 \\
\hline$r$ & $\ldots$ & Energy extinction coefficient (Eqn 10) & 0.398 \\
\hline $\mathrm{RE}$ & $\begin{array}{l}\mathrm{g} \mathrm{C} \mathrm{m}^{-2} \mathrm{day}^{-1} \\
\quad \mu \mathrm{mol} \mathrm{CO} 2 \mathrm{~m}^{-2} \mathrm{~s}^{-1}\end{array}$ & Ecosystem respiration from Leuning et al. (2005) & \\
\hline$R_{\mathrm{L}}$ & $\mathrm{MJ} \mathrm{m}^{-2}$ day $^{-1}$ & Long-wave radiation & \\
\hline$R_{\mathrm{N}}$ & $\mathrm{MJ} \mathrm{m}^{-2}$ day $^{-1}$ & Net radiation & \\
\hline $\mathrm{s}$ & $\mathrm{Pa} \mathrm{K}^{-1}$ & $\begin{array}{l}\text { Slope of the curve relating water vapour saturation } \\
\text { and temperature }\end{array}$ & \\
\hline SWC & $\mathrm{mm}$ & Soil water content (Table 2) & \\
\hline $\mathrm{t}$ & day & Time step & \\
\hline$T$ & $\mathrm{~mm}_{\text {day }}{ }^{-1}$ & Transpiration & \\
\hline $\mathrm{T}_{\mathrm{a}}$ & ${ }^{\circ} \mathrm{C}$ & Average daily air temperature & \\
\hline $\mathrm{T}_{\mathrm{d}}$ & ${ }^{\circ} \mathrm{C}$ & Average daytime air temperature & \\
\hline $\mathrm{T}_{\mathrm{K}}$ & Kelvin & Absolute temperature & \\
\hline $\mathrm{T}_{\max }, \mathrm{T}_{\min }$ & ${ }^{\circ} \mathrm{C}$ & Maximum and minimum daily air temperature & Input \\
\hline $\mathrm{T}_{\mathrm{s}}$ & ${ }^{\circ} \mathrm{C}$ & Average soil temperature at $2 \mathrm{~cm}$ depth & Input \\
\hline TSR & $\mathrm{MJ} \mathrm{m}^{-2}$ day $^{-1}$ & Total solar radiation & Input \\
\hline$u$ & $\ldots$ & Constant in $\mathrm{s} / \gamma$ equation (Eqn 14 ) & 0.006 \\
\hline$z$ & $\mathrm{~mm}_{\text {day }}{ }^{-1}$ & Canopy storage of precipitation & 0.5 \\
\hline$\gamma$ & $\mathrm{Pa} \mathrm{K}-1$ & Psychrometer constant & \\
\hline$\Delta Q$ & $\mathrm{~mm} \mathrm{day}^{-1}$ & Change in plant-available moisture content per time step & \\
\hline$\varepsilon$ & g dry wt $\mathrm{MJ}^{-1}$ & Maximum light-use efficiency & 0.34 \\
\hline$\lambda$ & $\mathrm{MJ} \mathrm{kg}^{-1}$ & Latent heat of vaporisation & 2.47 \\
\hline
\end{tabular}


McMurtrie et al. (1990), both are assumed to be constant. Net radiation $R_{\mathrm{N}}$ is calculated as a fraction of total solar radiation $\left(R_{\text {TOTAL }}\right)$ unreflected by surfaces minus long-wave radiation,

$$
R_{\mathrm{n}}=R_{\text {TOTAL }}(1-\text { albedo })-R_{\mathrm{L}},
$$

where the surface reflectance factor (albedo) is assumed to be constant. Long-wave radiation $R_{\mathrm{L}}$ is calculated as a function of the average temperature in daylight hours $\left(\mathrm{T}_{\mathrm{d}}\right)$,

$$
R_{\mathrm{L}}=m p\left(q-\mathrm{T}_{\mathrm{d}}\right),
$$

where $m, p$ and $q$ are constants. The average $\mathrm{T}_{\mathrm{d}}$ is calculated using temperature maximum $\left(\mathrm{T}_{\max }\right)$ and minimum $\left(\mathrm{T}_{\min }\right)$ values in a Taylor expansion formulation,

$$
\mathrm{T}_{\mathrm{d}}=\left(\mathrm{T}_{\max }+\mathrm{T}_{\min }\right) / 2+\left(\mathrm{T}_{\max }+\mathrm{T}_{\min }\right) / 3 \pi .
$$

This daytime temperature is used to calculate the energy terms involved in soil evaporation: the increase of latent heat content per increase of sensible heat content of saturated air at ambient temperature, the ratio of the slope of the curve relating water vapour saturation and temperature (s) and the psychrometer constant $(\gamma)$,

$$
e=\mathrm{s} / \gamma=c \exp \left(d \mathrm{~T}_{\mathrm{d}} / \mathrm{T}_{\mathrm{K}}\right) /\left(h+u \mathrm{~T}_{\mathrm{d}}\right) \mathrm{T}_{\mathrm{K}}^{2},
$$

where $c, d, h$ and $u$ are constants, and the temperature is in Kelvin. The factor $f_{\text {Wtop }}$ in Eqn 10 is a modifier that depends on the water content of the top layer of soil,

$$
f_{\text {Wtop }}=\left(Q 1 / Q_{\max }-F_{\text {wpmin }}\right) /\left(F_{\text {wpmax }}-F_{\text {wpmin }}\right),
$$

where $f_{\text {Wtop }}$ decreases from 1 towards 0 as the plant-available water in the top layer $(Q 1)$ declines from the threshold $F_{\text {wpmax }}$, denoting the maximum fraction of $Q 1_{\text {max }}$, the maximum plantavailable water in the top layer, where $F_{\text {wpmax }}$ and $F_{\text {wpmin }}$ are the same parameters used in Eqn 6. The plant-available water in the upper $1.20 \mathrm{~m}$ of the soil profile, denoted $Q 2$, was also simulated so it could be compared with the measurements.

Daily transpiration is simulated using a water-use efficiency formulation (Dewar 1997),

$$
T=\operatorname{NPP} D / q_{0},
$$

where $q_{0}$ is the intrinsic water-use efficiency $\left(\mathrm{g} \mathrm{C} \mathrm{kPa} \mathrm{mm}^{-1}\right)$. Daily transpiration extracts soil water from the $0-0.15 \mathrm{~m}$ and $0-1.20 \mathrm{~m}$ layers and from the deeper total root zone. The fractions of water uptake from the $0-0.15 \mathrm{~m}$ and $0-1.20 \mathrm{~m}$ layers are $f 1$ and $f 2$, respectively; if the sum of $f 1$ and $f 2$ is less than 1 then transpiration extracts water partly from a soil layer deeper than $1.20 \mathrm{~m}$. Daily water flux $F_{\mathrm{w}}$ was calculated as,

$$
F_{\mathrm{w}}=T+E+I,
$$

For simplicity, the plant biomass components (leaves, fine roots and woody components) are held constant.

\section{Model parameterisation}

In this section we describe how the measured values of $F_{\mathrm{c}}, F_{\mathrm{w}}$ and soil moisture were used with the meteorological data to estimate the parameters for the model. Hourly data were available for derivations of daily and daytime totals. These empirical data were investigated for evidence of relationships represented in the model framework. In particular, we were interested in examining whether variation in vapour-pressure deficit and soil water affected productivity. Overall parameters were estimated from plots of empirical data or by fitting the model to multiple forest variables, or they were taken from the literature, as described in the following subsections.

\section{Effects of vapour-pressure deficit and soil moisture}

The rationale in the model is that when the vapour-pressure deficit is large the water loss from leaves may exceed the water supply to the leaves, even under high to moderate levels of soil moisture, and this could reduce leaf water potentials and, hence, stomatal conductance (e.g. Fuchs and Livingston 1996). To establish whether or not the vapour pressure modifier $\left(f_{\mathrm{D}}\right)$ in Eqn 5 was relevant to this site, we isolated $\mathrm{CO}_{2}$ flux measurements $\left(F_{\mathrm{c}}\right)$ when $\mathrm{D}>1 \mathrm{kPa}$ and when soil water content in the $0-1.20 \mathrm{~m}$ layer exceeded $299 \mathrm{~mm}$. This was done to see if there was any relationship between $F_{\mathrm{c}}$ and $\mathrm{D}$ when the soil water content was not low. We also examined this relationship after normalising $F_{\mathrm{c}}$ by dividing it by TSR $\left(\mathrm{MJ} \mathrm{m}^{-2}\right.$ day $\left.^{-1}\right)$ because light can dominate control of stomatal conductance at different times of the day (e.g. Oren et al. 1999). Thus, daily $\mathrm{CO}_{2}$ flux measurements were filtered and used to estimate the maximum $\left(D_{\max }\right)$ and minimum $\left(D_{\min }\right)$ parameter values in Eqn 5 ; hence, the effect of D on NPP was incorporated in the model through Eqn 5 by setting $D_{\max }$ and $D_{\min }$ values.

We looked for evidence of any soil water limitation on $\mathrm{CO}_{2}$ flux measurements rather than on $\mathrm{H}_{2} \mathrm{O}$ flux measurements to avoid water evaporation from surfaces interfering with the canopy conductance signal. This was done simply by plotting $F_{\mathrm{c}}$ against the soil water content in the $0-1.20 \mathrm{~m}$ layer. $\mathrm{CO}_{2}$ flux measurements normalised by dividing $F_{\mathrm{c}}$ by TSR and then plotted against soil water content in the $0-1.20 \mathrm{~m}$ layer were also examined. In addition, we examined the rate of water extraction during drying cycles. In essence, soil moisture drying cycles were isolated from the data series, and the rate of soil water extraction was estimated with linear regression. Drying cycles were isolated using negative soil moisture differences occurring over consecutive days. Mean differences (and their s.d.) were calculated and the first difference at the beginning of each drying cycle was compared with the mean. If this initial extraction rate was more than 2 s.d. faster than the mean for the entire drying cycle then it was denoted as being significantly different from the mean. There were several cases where a significant difference occurred, so initial extraction rates in all cases were not included in the linear regression estimations of mean extraction rate. Linear regressions were only fitted to soil moisture measurements made over the drying cycle periods and the slope was taken to be an estimate of the extraction rate $\left(\mathrm{mm} \mathrm{day}^{-1}\right)$. Extraction rates were normalised by dividing by the vapour-pressure deficit.

The effect of variation in soil water content on NPP was incorporated into the model via Eqn 6 by setting the parameters, maximum plant available water $\left(Q_{\max }\right)$ and the fraction of maximum soil water at which soil water begins to affect NPP $\left(F_{\text {wpmax }}\right)$. 


\section{Effect of temperature}

Early in the parameterisation procedure, when the temperature effect was set at 1 (no effect), measured $\mathrm{CO}_{2}$ flux lagged simulated $\mathrm{CO}_{2}$ flux. A plot of TSR and temperature together versus time revealed that the temperature tended to lag the solar radiation. This was the motivation for including $f_{\mathrm{T}}$ in the model.

\section{Water balance, light-use efficiency and water-use efficiency}

Effective precipitation, daily precipitation minus canopy interception $(P-I)$, flows into the soil root zone; $I$ was simulated by setting the $z$ parameter in Eqn $9 \mathrm{~b}$ constant (Table 1). Daily transpiration $(T)$ is the other component of $F_{\mathrm{w}}$, as represented in Eqn 17 , and the $f 1$ parameter adjusts what fraction of $T$ is taken from the top soil layer. Evaporation from soil is a function of $f_{\text {Wtop }}$ (Eqn 15), which depends on soil moisture in the top soil layer.

The maximum plant-available water in the upper $1.20 \mathrm{~m}$ of soil, denoted $Q 2_{\max }$, was estimated from measurements of soil water (to a depth of $1.20 \mathrm{~m}$ ) as the maximum soil water level $(454 \mathrm{~mm})$ minus the lowest soil water level $(245 \mathrm{~mm})$. The maximum plant-available water in the uppermost $0.15 \mathrm{~m}$ $\left(Q 1_{\text {max }}\right)$ was similarly estimated.

Estimates of other parameter values involved fitting the model to multiple forest variables. We calculated RE from Eqn 2, daily GPP from Eqn 1 and measurements of $F_{\mathrm{c}}$ and daily net primary productivity $\left(\mathrm{NPP}^{\prime}\right)$ by assuming $\mathrm{CUE}=0.5$ (Gifford 1992, 2003; Dewar et al. 1998, 1999; Waring et al. 1998; $\left.\mathrm{NPP}^{\prime}=0.5 \mathrm{GPP}\right)$. The maximum light-use efficiency parameter $\varepsilon$ was estimated as the maximum slope of a plot of NPP' versus APAR (cf. Medlyn et al. 2003), where $\mathrm{NPP}^{\prime}$ was derived as GPP $\times$ CUE and APAR was simulated using Eqn 4. The intrinsic water-use efficiency parameter $q_{0}$ was estimated after $\varepsilon$ by changing $q_{0}$ until a reasonable simulation was obtained for measurements (daily values) of $F_{\mathrm{c}}, F_{\mathrm{w}}$ and soil moisture in the $0-0.15 \mathrm{~m}$ and $0-1.20 \mathrm{~m}$ layers. Both $q_{0}$ and $\varepsilon$ were held constant over wet and dry years.

The maximum plant-available water $\left(Q_{\max }\right)$ was increased above $Q 2_{\text {max }}$ to achieve simulations of $F_{\mathrm{w}}$ that were equivalent in wet and dry years, but simulations of $F_{\mathrm{c}}$ that were diminished in the dry year, and simulated soil moisture for the $0-0.15 \mathrm{~m}$ and $0-1.20 \mathrm{~m}$ layers so that all four model outputs $\left(F_{\mathrm{w}}, F_{\mathrm{c}}, Q 1\right.$ and $\left.Q 2\right)$ were reasonable fits to their measured records. This implied that the forest had access to water deeper than $1.20 \mathrm{~m}$.

\section{Leaf area index}

Leaf area index (LAI) was reported by Leuning et al. (2005) as 1.4 for overstorey and 1.0 for understorey so LAI was set constant at 2.4 for simulating the daily $F_{\mathrm{c}}, F_{\mathrm{w}}, Q 1$ and $Q 2$ corresponding to the daily totals from the hourly measurements. Variation in rates of litterfall suggests that there may have been variation in LAI between wet and dry years, but variation in rates of litterfall and LAI do not always correlate well, especially because of leaf retention in evergreen species. It is known that drought and storm events can have marked effects on the rates of monthly litterfall, but have little impact on LAI (Dye et al. 2004). We held LAI constant for simulations across wet and dry years because this supported our strategy of keeping the modelling analysis simple and transparent. We did, however, want to test the sensitivity of the modelled system to variable LAI so we added LAI variability into the sensitivity analysis.

\section{Sensitivity analysis}

The UNCSIM software package (http://www.uncsim.eawag.ch, version 1.1c, accessed 5 April 2005) (Brun et al. 2001; Reichert 2006) was interfaced with the model and used to calculate the sensitivity indices described below.

This sensitivity analysis assumes that the vector of model results $\mathrm{y}=\left(y_{1}, ., y_{\mathrm{n}}\right)^{\mathrm{T}}$ is a deterministic function of the model parameters $\theta_{M}=\left(\theta_{1}, \ldots, \theta_{m}\right)^{\mathrm{T}}: \mathrm{y}_{M}\left(\theta_{M}\right)$, where $M$ indicates the model. In a local neighbourhood of a particular choice of parameter values, $\theta_{\mathrm{M}}$, the model equations can be approximated linearly,

$$
\mathrm{y}_{M}\left(\theta_{M}\right) \approx y_{M}\left(\theta_{M} *\right)+\partial y_{M} / \partial \theta_{M}^{T}\left(\theta_{M} *\right)\left(\theta_{M}-\theta_{M} *\right) .
$$

The CALCLOCSENS routine of UNCSIM calculates the sensitivity as the derivative $\left(\partial y_{M, i} / \partial \theta_{M, j}\right)$ of the model results $y_{\mathrm{M}, \mathrm{i}}$ with respect to the parameter $\theta_{\mathrm{M}, \mathrm{j}}$ evaluated at the parameter value $\theta_{\mathrm{M}}$ * The derivatives are calculated approximately by a finite difference approximation with user-specified parameter increments. Sensitivity $s_{\mathrm{i}, \mathrm{j}}$ is computed as,

$$
s_{i, j}=\Delta \theta_{M, j} / s_{i}\left(\partial y_{M, i} / \partial \theta_{M, j}{ }^{T}\right), s_{j}=\left(s_{1, j}, ., s_{n, j}\right)^{T},
$$

where $\Delta \theta_{\mathrm{M}, \mathrm{j}}$ represents the a priori uncertainty range in the parameter $\theta_{\mathrm{M}, \mathrm{j}}$ (Brun et al. 2001), and $\mathrm{sc}_{\mathrm{i}}$ is a scaling factor that represents a typical order of magnitude for the output variable $y_{\mathrm{M}, \mathrm{i}}$. The sensitivity measure $\delta^{\mathrm{msqr}}$, computed and used to rank sensitivities of parameters, is defined as,

$$
\delta_{j}^{\mathrm{msqr}}(\theta)=\sqrt{\frac{1}{\mathrm{n}} \sum_{\mathrm{i}=1}^{\mathrm{n}} \mathrm{s}_{\mathrm{ij}}^{2}} .
$$

The a priori parameter value uncertainty $\Delta \theta_{\mathrm{M}, \mathrm{j}}$ was set to $\theta_{\mathrm{M}}{ }^{*} \pm 0.2 \times \theta_{\mathrm{M}}{ }^{*}$. In the CALCLOCSENS routine, this meant that the parameter values $\left(\theta_{M^{*}}\right)$ were all increased by $20 \%$, one-by-one, to determine the sensitivity of the model output. In the present study we used $\delta^{\mathrm{msqr}}$ as a measure of sensitivity on an inter-annual timeframe, and $s_{\mathrm{i}, \mathrm{j}}$ was used to investigate the sensitivity on an intra-annual timeframe (Pepper et al. 2007). We determined the sensitivity of the modelled GPP to the CUE parameter, and of the modelled NPP to 12 other key model parameters that productivity was sensitive to.

To add variability in LAI into the sensitivity analysis we ran the sensitivity analysis with constant LAI and then repeated it with variable LAI. Instead of changing LAI by $20 \%$, like the model parameters, we derived a variable record of LAI and input this into the model. The variable record of LAI was based on variation found in measured litterfall. Litterfall data were collected on an approximately monthly basis (H. Keith, unpubl. data; Kirschbaum et al. 2007). These data were converted to daily rates of litterfall and interpolated linearly as constant rates between collection dates. We calculated the quotient of these rates at similar times of the year as, rate(dry year)/rate(wet year), which represented dry-year rates in proportion to wet-year rates; that is, a dry-year quotient of the preceding year. We assumed that LAI was constant at 2.4 under the pattern of wet-year litterfall 
rates and we used 2.4 divided by our quotient to generate variability in LAI over the dry year. We fully acknowledge that the LAI variation is unrealistic, which is why its use has been confined to the sensitivity analysis alone. Litterfall is often assumed to be proportional to canopy biomass (e.g. Comins and McMurtrie 1993; Dye et al. 2004), but this treatment implies that increased litterfall associated with water stress in the dry year leads to reduced LAI (e.g. Rascher et al. 2004).

\section{Results}

First, we present results from the analyses of the data because these were an important step in the model parameterisation procedure. This procedure provided a model calibrated to the Tumbarumba flux site, which was used in our sensitivity analysis. Estimated parameters are listed in Table 2. Results from the sensitivity analysis with constant LAI, and then repeated with variable LAI, are presented in the second part of this section.

\section{Model parameterisation}

\section{Effects of vapour-pressure deficit and soil moisture}

The approach taken with parameter estimation revealed evidence of water-related effects on productivity. Slight negative relationships between $F_{\mathrm{c}}$ versus $\mathrm{D}$ (slope not significantly different from zero, $P=0.104$ ) and $F_{\mathrm{c}}$ versus $\mathrm{D} / \mathrm{TSR}$ (slope was significantly different from zero, $P=0.027$ ) were found (Fig. $2 a$ ). $F_{\mathrm{c}}$ decreases by $\sim 30 \%$ over the range $1-3 \mathrm{kPa}$, so $D_{\max }$ in Eqn 5 would be $\sim 7.45 \mathrm{kPa}$ and $D_{\min }$ would be set at $1 \mathrm{kPa}$, so that $f_{\mathrm{D}}$ scales from 1 at $1 \mathrm{kPa}$ down to $(1-0.3=) 0.7$ at $3 \mathrm{kPa}$ (and down to 0 at $7.45 \mathrm{kPa}$ ). To incorporate this $\mathrm{D}$ effect into the model via Eqn 5 we set the maximum to $7.45 \mathrm{kPa}$ and the minimum to $1 \mathrm{kPa}$ (Table 2).

There was some structure to the $\mathrm{CO}_{2}$ flux versus soil moisture plots. Weak evidence of an effect of soil water on $F_{\mathrm{c}}$ was strengthened using the $F_{\mathrm{c}}$ measurements that were normalised to TSR (data not shown), and this evidence was similar for rates of soil water extraction. As the soil moisture content increased from $\sim 245 \mathrm{~mm}$ the uppermost normalised $F_{\mathrm{c}}$ data tended to increase. Thus, a limitation to $F_{\mathrm{c}}$ became apparent as soil moisture in the $0-1.20 \mathrm{~m}$ layer drops below $\sim 320 \mathrm{~mm}$. Because this could have resulted from a soil moisture effect on respiration or on GPP (Eqn 1), we checked a plot of night-time $\mathrm{CO}_{2}$ flux measurements against soil moisture and there was no relationship, which is consistent with Leuning et al. (2005).
Extraction rates estimated from drying cycles ranged from close to $1.1 \mathrm{~mm} \mathrm{day}^{-1}$ up to nearly $4.8 \mathrm{~mm} \mathrm{day}^{-1}$ (Table 3 ; Rate); extraction rates normalised to the vapour-pressure deficit $\left(\mathrm{mm} \mathrm{kPa}^{-1} \mathrm{day}^{-1}\right)$ ranged from approximately 0.01 to $0.1 \mathrm{~mm} \mathrm{kPa}^{-1}$ day $^{-1}$ (Fig. 2b). High normalised extraction rates seemed to be constrained by soil moisture levels below $320 \mathrm{~mm}$ approximately to the minimum of $245 \mathrm{~mm}$ (Fig. $2 b$ ). There were more of these drying cycles in the dry year in spring and autumn, but the rates of extraction were similar in both years (Table 3 ).

\section{Effects of temperature}

Incorporating a temperature effect on NPP into the model improved the simulated $F_{\mathrm{c}}$ (Fig. 1) by reducing the lag observed between the measured and simulated $F_{\mathrm{c}}$ without the temperature effect (i.e. $f_{\mathrm{T}}$ held at 1 ) and therefore dominated by solar radiation.

\section{Water balance, light-use efficiency and water-use efficiency}

Maximum light-use efficiency $(\varepsilon)$ was estimated as the maximum slope (0.34) of the $\mathrm{NPP}^{\prime}$ versus APAR plot (data not shown). The parameter $z$ in Eqn $9 \mathrm{~b}$ for maximum canopy interception $\left(I_{\max }\right)$ was set at 0.5 after McMurtrie et al. (1990). Intrinsic water-use efficiency $\left(q_{0}\right)$ was estimated after $\varepsilon$, after $k$ was set at 0.5 . The $f 1$ parameter describing the fraction of transpiration taken from the top $(0-0.15 \mathrm{~m})$ soil layer was estimated after $\varepsilon$ and $q_{0}$ to simulate soil water in the top layer. The estimated parameter values are provided in Table 2 .

Maximum plant-available water $\left(Q_{\max }\right)$ was an interesting result. To obtain a reasonable fit to the measured records of $F_{\mathrm{c}}, F_{\mathrm{w}}$, $Q 2$ and $Q 1$, and to simulate reasonable annual values of $F_{\mathrm{c}}$ and $F_{\mathrm{w}}$ in both wet and dry years, we needed to set $Q_{\max }$ greater than $Q 2_{\text {max }}$. This implies that substantial water in addition to that available in the first $1.20 \mathrm{~m}$ depth of soil was probably available to the trees. We examined this further using measured records, and calculated the annual water input as the sum of the measured precipitation and the change in measured plant-available water in the $1.20 \mathrm{~m}$ layer $(\mathrm{P}+\Delta Q 2)$ for wet and dry years and compared this to the annual water output $\left(F_{\mathrm{w}}\right)$. We found that annual input exceeded annual output in the wet year by $\sim 50 \%$, but in the dry year they were almost equal. Similarly, we calculated water input and water output, both expressed as 7-day running means with a daily time step, and water output exceeded water input 155 days in the wet year compared with 220 days in the dry year.

Table 2. Model parameters estimated using soil moisture, gas flux and meteorological measurements

\begin{tabular}{lllc}
\hline Symbol & Units & Description & Value \\
\hline$\varepsilon$ & $\mathrm{g} \mathrm{DW} \mathrm{MJ}$ & 0.34 \\
$D_{\max }, D_{\min }$ & $\mathrm{kPa}$ & Maximum light-use efficiency & $7.45,1.0$ \\
$Q_{\max }$ & $\mathrm{mm}$ & Maximum and minimum parameters in Eqn 5 & 350 \\
$Q 1_{\max }$ & $\mathrm{mm}$ & Maximum plant-available water & 44.1 \\
$Q 2_{\max }$ & $\mathrm{mm}$ & Maximum plant-available water in the 0-0.15 m soil layer & 170 \\
$F_{\mathrm{wpmax}}$ & $\ldots$ & Maximum plant-available water in the 0-1.20 soil layer & 0.3 \\
$F_{\mathrm{wpmin}}$ & $\ldots$ & Fraction of $Q_{\max }$ below which $f_{\mathrm{w}}<1$ & -0.5 \\
$f 1, f 2$ & & Adjusts slope of $f_{\mathrm{w}}$ versus $Q$ & $0.1,0.5$ \\
& & Fraction of transpiration extracted from the 0-0.15 & 0.5 \\
$q_{0}$ & $\mathrm{~g} \mathrm{C} \mathrm{kPa} \mathrm{m}{ }^{-2} \mathrm{~mm}^{-1}$ & and 0-1.20 m soil layers & 1.8 \\
albedo & $\cdots$ & Intrinsic water-use efficiency & 0.2 \\
\hline
\end{tabular}



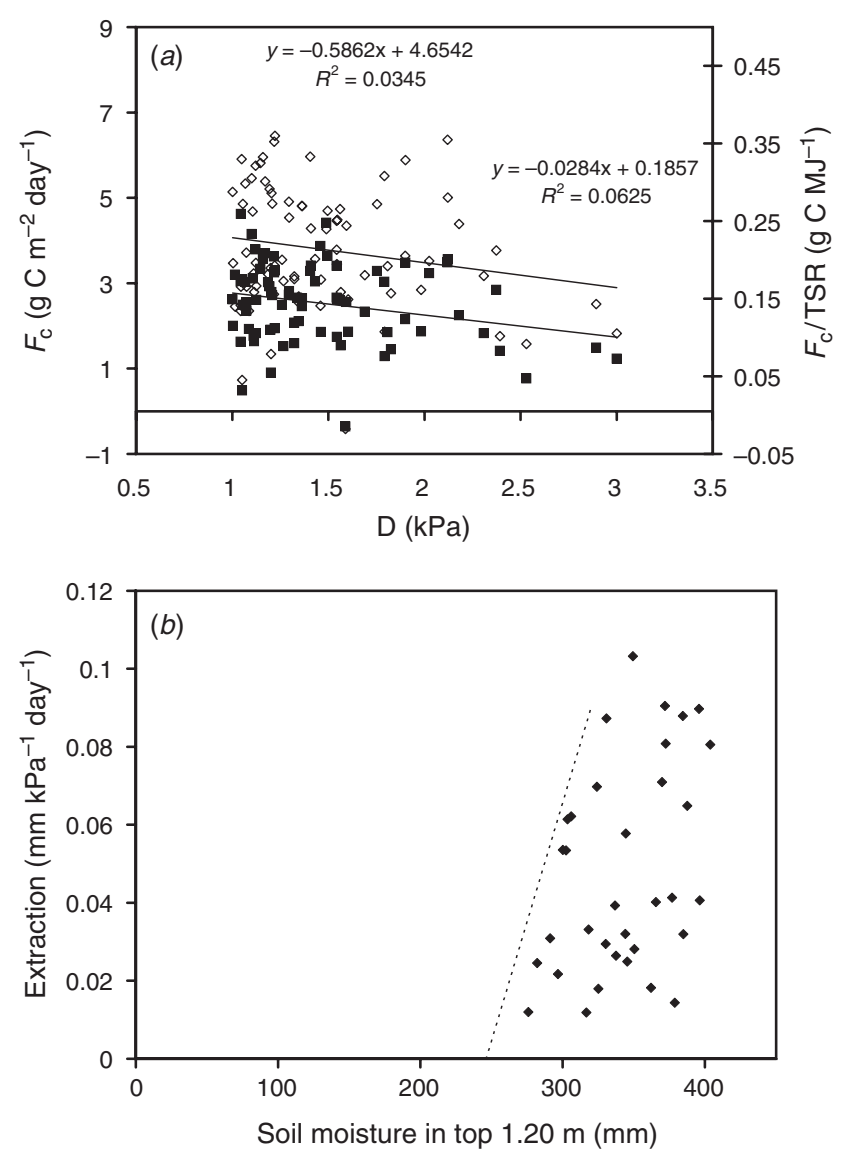

Fig. 2. (a) Linear regression on $\mathrm{CO}_{2}$ flux $\left(F_{\mathrm{c}}\right)$ measurements versus vapourpressure deficit (D) (open diamonds) and on $F_{\mathrm{c}}$ normalised to total solar radiation (TSR) versus $\mathrm{D}$ (closed squares) using $F_{\mathrm{c}}$ when $\mathrm{D}>1 \mathrm{kPa}$ and soil water content $>299 \mathrm{~mm}$. (b) Normalised soil water extraction rates at different soil moisture levels. Soil water extraction rates were estimated as the slope of the linear regressions on soil moisture observations over drying cycles (time intervals comprised consecutive days without rainfall). Extraction rates were normalised by dividing by $\mathrm{D}$. The line indicates possible soil moisture constraints on soil water extraction.

On an annual basis, water supply adequately matched water use, but on a weekly basis water use often exceeded the water available from precipitation and storage in the upper $1.20 \mathrm{~m}$, and this occurred more often in the dry year.

Overall, reasonable simulations of $Q 1, Q 2, F_{\mathrm{w}}$ and $F_{\mathrm{c}}$ were achieved (Fig. 1) with the estimated parameter set (Table 2). Simulations of water flux were similar for wet and dry years, but simulations of $\mathrm{CO}_{2}$ flux were lower in the dry year (Fig. 1b,c). It is interesting to note that there was a discrepancy between the modelled and measured $Q 1$ and $Q 2$ for considerable periods (weeks) in both wet and dry years.

\section{Leaf area index}

The variation that was generated in LAI to reflect variation in litterfall rates relative to the wet year resulted in a LAI that changed abruptly after each collection date in the dry year, increasing to as high as 4.5 and decreasing to as low as 1.42 (Fig. 1b). The introduction of this variability resulted in lower LAI averaged over the growing season or over the entire dry year. This crude estimate of LAI with abrupt changes was favoured for the sensitivity analysis and was used deliberately to increase the detection of any effect of LAI on $\mathrm{CO}_{2}$ flux, productivity or water use. Simulated $F_{\mathrm{c}}$ and NPP were positively affected by the variation in LAI, but simulated $F_{\mathrm{w}}$ was little affected.

\section{Sensitivity analysis \\ Inter-annual sensitivity (with constant LAI)}

The 13 model parameters to which productivity was most sensitive are listed in Table 4. Maximum light-use efficiency $(\varepsilon)$ was ranked the highest and albedo was the lowest out of the 13 parameters. This sensitivity was based on $\delta^{\mathrm{msqr}}$ calculated (Eqn 20) across both wet and dry years. There were also differences in the sensitivities between wet and dry years based on $\delta^{\text {msqr }}$ calculated for each year. For example, productivity was more sensitive to variation in $\varepsilon$, the light extinction coefficient $(k)$ and CUE in the wet year, but the other parameters listed in Table 4 were more important in the dry year. Light-use efficiency is a key parameter in the model (Eqn 3) linking absorbed light and productivity. The lightextinction coefficient affects the fraction of incident light that is absorbed by the canopy (Eqn 4$)$. These three parameters $(\varepsilon, k$, CUE) were more important in the wet year because water-limiting effects on productivity were smaller in the wet year compared with the dry year. Maximum plant available water $\left(Q_{\max }\right)$ and water-use efficiency $\left(q_{0}\right)$ were not important at all in the wet year, but became substantially more important in the dry year. Maximum plant available water $Q_{\max }$ (Eqn 6) has an important influence on the soil-water factor $f_{\mathrm{W}}$ because $f_{\mathrm{W}}$ begins to decrease once the $Q / Q_{\max }$ fraction drops below its critical value $\left(F_{\text {wpmax }}\right)$. Thus, the soil-water factor $f_{\mathrm{W}}$ became more important in the dry year because a $20 \%$ increase in $Q_{\max }$ meant that the $Q / Q_{\max }$ fraction spent more time below its critical value $F_{\text {wpmax }}$. Wateruse efficiency $\left(q_{0}\right)$ had an important influence on productivity in the dry year because a $20 \%$ increase in $q_{0}$ reduced transpiration (Eqn 16), which led to increased plant-available water and a diminished soil-water effect in the dry year. The parameters $D_{\max }$ and $D_{\text {min }}$ in Eqn 5 determine how the vapour-pressure deficit effect $\left(f_{\mathrm{D}}\right)$ scales with changes in D. These parameters were more important in the dry year, which was warmer and less humid, because D was higher more often compared with the wet year. The remaining parameters listed in Table 4 all had a negligible effect on productivity in the wet year compared with the dry year. The parameters $F_{\text {wpmax }}$ and $F_{\text {wpmin }}$ in both Eqns 6 and 15 determine how $f_{\mathrm{W}}$ and $f_{\mathrm{Wtop}}$ scale with changes in $Q$ and $Q 1$, respectively. These parameters were also more important in the dry year because plant-available water $(Q, Q 1)$ was lower compared with the wet year. Maximum plant-available water in the top soil layer $\left(Q 1_{\max }\right)$ was not very important overall, but became more important in the dry year because it effectively reduced the loss of plant-available water, which led to reductions in $f_{\text {Wtop }}$ and soil water evaporation (Eqn 10). The parameter governing the fraction of transpiration extracted from the top soil layer $(f 1)$ was also of minor importance, but became more important in the dry year for similar reasons; it resulted in less water being removed by surface evaporation from the top soil layer and thus in a small positive gain to the pool of plant-available 
Table 3. Mean \pm s.d. of soil moisture differences between consecutive days within each drying cycle (see Fig. 1a) $n$, the number of differences calculated for each drying cycle; Rate, the soil water extraction rate estimated as the slope of the linear regression fitted to soil water content measurements in each drying cycle; Initial SWC, the soil water content at the beginning of each drying cycle; Season, indicates the season in the southern hemisphere

\begin{tabular}{|c|c|c|c|c|c|c|c|}
\hline$\overline{\text { Day }}$ & Mean $\left(\mathrm{mm} \mathrm{day}^{-1}\right)$ & s.d. & $n$ (day) & $\begin{array}{c}\text { Significance } \\
\text { (mean }-2 \times \text { s.d.) }\end{array}$ & Rate $\left(\mathrm{mm} \mathrm{day}^{-1}\right)$ & Initial SWC (mm) & Season \\
\hline 200 & -1.38 & 0.850 & 4 & $\mathrm{~ns}$ & -1.387 & 396 & Winter \\
\hline 208 & -1.22 & 0.243 & 4 & $\mathrm{~ns}$ & -1.246 & 388 & Winter \\
\hline 269 & -1.49 & 0.834 & 4 & sig & -1.067 & 396 & Spring \\
\hline 323 & -2.51 & 1.123 & 4 & $\mathrm{~ns}$ & -2.748 & 404 & Spring \\
\hline 343 & -1.48 & 1.004 & 4 & ns & -1.763 & 385 & Summer \\
\hline 348 & -1.45 & 0.844 & 8 & ns & -1.610 & 379 & Summer \\
\hline 362 & -1.42 & 0.993 & 4 & $\mathrm{~ns}$ & -1.410 & 362 & Summer \\
\hline 373 & -2.03 & 0.708 & 6 & sig & -1.777 & 344 & Summer \\
\hline 405 & -1.87 & 1.250 & 5 & ns & -1.986 & 377 & Summer \\
\hline 424 & -3.28 & 1.980 & 9 & ns & -3.447 & 372 & Summer \\
\hline 434 & -5.03 & 4.785 & 4 & $\mathrm{~ns}$ & -4.794 & 344 & Autumn \\
\hline 439 & -2.84 & 1.172 & 4 & $\mathrm{~ns}$ & -2.599 & 330 & Autumn \\
\hline 454 & -2.68 & 3.434 & 4 & $\mathrm{~ns}$ & -3.910 & 339 & Autumn \\
\hline 460 & -1.32 & 0.310 & 4 & $\mathrm{~ns}$ & -1.285 & 337 & Autumn \\
\hline 508 & -2.13 & 1.268 & 14 & sig & -1.802 & 372 & Autumn \\
\hline 556 & -2.78 & 1.613 & 6 & sig & -2.244 & 384 & Winter \\
\hline 601 & -1.86 & 1.004 & 4 & ns & -1.778 & 366 & Winter \\
\hline 618 & -2.95 & 1.726 & 5 & sig & -2.255 & 370 & Spring \\
\hline 646 & -1.31 & 0.412 & 4 & ns & -1.373 & 345 & Spring \\
\hline 654 & -1.97 & 0.940 & 6 & $\mathrm{~ns}$ & -2.046 & 350 & Spring \\
\hline 664 & -1.83 & 0.925 & 9 & $\mathrm{~ns}$ & -1.927 & 337 & Spring \\
\hline 675 & -1.35 & 0.668 & 13 & ns & -1.271 & 317 & Spring \\
\hline 709 & -3.56 & 0.891 & 5 & sig & -3.270 & 331 & Summer \\
\hline 718 & -4.08 & 3.313 & 6 & sig & -2.801 & 325 & Summer \\
\hline 732 & -5.30 & 2.357 & 5 & sig & -4.150 & 324 & Summer \\
\hline 739 & -1.95 & 1.160 & 11 & $\mathrm{~ns}$ & -2.239 & 297 & Summer \\
\hline 753 & -2.09 & 1.668 & 6 & ns & -1.766 & 276 & Summer \\
\hline 772 & -4.60 & 2.397 & 4 & sig & -3.3909 & 282 & Summer \\
\hline 791 & -2.56 & 1.073 & 5 & sig & -2.3144 & 302 & Autumn \\
\hline 800 & -2.19 & 0.939 & 4 & sig & -1.7749 & 291 & Autumn \\
\hline 810 & -3.21 & 1.678 & 6 & sig & -2.5254 & 303 & Autumn \\
\hline 823 & -3.99 & 2.461 & 4 & sig & -2.7541 & 300 & Autumn \\
\hline 836 & -2.77 & 2.799 & 10 & sig & -1.8045 & 318 & Autumn \\
\hline 850 & -2.09 & 0.371 & 5 & sig & -1.9259 & 306 & Autumn \\
\hline
\end{tabular}

water. Small variations to canopy-intercepted water loss or net radiation reaching the soil surface, simulated via $z$ or albedo variation, respectively, had minor effects only in the dry year.

\section{Inter-annual sensitivity (with variable LAI)}

When variable LAI was incorporated into the sensitivity analysis, the sensitivity of productivity decreased for parameters ranked 10 or above (Table 4). Thus, variable LAI tended to increase the difference in sensitivity between wet and dry years for $\varepsilon, k$ and CUE, but decrease the difference for the other 'moisture-related' parameters (Table 4). The ranking changed only slightly, in positions 11 and 12 , when the sensitivity of albedo decreased proportionally more than it did for $z$.

\section{Intra-annual sensitivity (with constant LAI)}

The daily values of sensitivity ( $s_{\mathrm{ij}}$; Eqn 19$)$ shown in Fig. 3 provide additional information to that summarised in the $\delta^{\mathrm{msqr}}$ values presented in Table 4. Fig. 3 highlights when parameters and their related processes became important with respect to productivity at different times of the year, over both the wet and dry years. For most of the time, productivity, GPP or NPP was very sensitive to CUE or $\varepsilon$ and $k$, respectively (Fig. $3 a$ ), but NPP sensitivity to both the 'light-related' parameters $\varepsilon$ and $k$ was diminished almost completely when plant-available water became low in the second year and productivity became sensitive to maximum water availability $\left(Q_{\max }\right)$; a $20 \%$ increase in $Q_{\max }$ had a very important impact on NPP when soil moisture was lowest. Increases in $D_{\max }$ and $D_{\min }$ decreased the effect of D on NPP, except during the driest period of the dry year. Fig. $3 c$ shows that NPP was frequently impacted by the vapour-pressure deficit in the middle and second half of the growing season when D was high. Understandably, NPP was sensitive to processes related to soil moisture at times of the year when the plant-available water was lowest. An increase in the maximum plant-available water had the greatest impact on NPP during the driest period occurring over the entire 2 years (Fig. $3 a, b$ ). This was also the case for water-use efficiency 
Table 4. Inter-annual sensitivity of simulated productivity (net primary productivity or gross primary productivity in the case of carbon-use efficiency (CUE)) to parameter variation, first using a constant leaf area index (LAI) and then using a variable LAI based on the $\delta^{\mathrm{msqr}}$ sensitivity measure (Eqn 20) for wet and dry years and for wet + dry years (the latter has been used to rank the sensitivity of the parameters)

$\delta^{\mathrm{msqr}}$ was calculated for the first 233 days of each growing season (days 187-419 and days 554-786 in Fig. 1) to avoid the period of discrepancy between the modelled and measured soil moisture values in the latter part of the dry year. A value of zero indicates that productivity was insensitive to variation in the particular parameter under the prevailing environmental conditions

\begin{tabular}{|c|c|c|c|c|}
\hline \multicolumn{5}{|c|}{ Inter-annual sensitivity with constant LAI } \\
\hline Rank & Parameter & Wet & Dry & Wet + dry \\
\hline 1 & $\varepsilon$ & 1.0449 & 0.9882 & 1.0169 \\
\hline 2 & $k$ & 0.5403 & 0.5111 & 0.5259 \\
\hline 3 & CUE & 0.5081 & 0.3725 & 0.4455 \\
\hline 4 & $Q_{\max }$ & 0 & 0.5074 & 0.3588 \\
\hline 5 & $q_{0}$ & 0 & 0.4489 & 0.3174 \\
\hline 6 & $D_{\min }$ & 0.0655 & 0.1412 & 0.1101 \\
\hline 7 & $D_{\max }$ & 0.0867 & 0.1119 & 0.1001 \\
\hline 8 & $F_{\text {wpmax }}$ & 0 & 0.1326 & 0.0938 \\
\hline 9 & $Q 1_{\max }$ & 0 & 0.0678 & 0.0480 \\
\hline 10 & $F_{\text {wpmin }}$ & 0 & 0.0670 & 0.0474 \\
\hline 11 & $f 1$ & 0 & 0.0196 & 0.0138 \\
\hline 12 & albedo & 0 & 0.0167 & 0.0118 \\
\hline 13 & $z$ & 0 & 0.0089 & 0.0063 \\
\hline \multicolumn{5}{|c|}{ Inter-annual sensitivity with variable LAI } \\
\hline Rank & Parameter & Wet & Dry & Wet + dry \\
\hline 1 & $\varepsilon$ & 1.0449 & 0.8482 & 0.9516 \\
\hline 2 & $k$ & 0.5403 & 0.4654 & 0.5043 \\
\hline 3 & CUE & 0.5081 & 0.3696 & 0.4442 \\
\hline 4 & $Q_{\max }$ & 0 & 0.3218 & 0.2276 \\
\hline 5 & $q_{0}$ & 0 & 0.2790 & 0.1973 \\
\hline 6 & $D_{\min }$ & 0.0655 & 0.1187 & 0.0959 \\
\hline 7 & $D_{\max }$ & 0.0867 & 0.0956 & 0.0913 \\
\hline 8 & $F_{\text {wpmax }}$ & 0 & 0.1196 & 0.0845 \\
\hline 9 & $Q 1_{\max }$ & 0 & 0.0533 & 0.0377 \\
\hline 10 & $F_{\text {wpmin }}$ & 0 & 0.0161 & 0.0114 \\
\hline 11 & $f 1$ & 0 & 0.0124 & 0.0088 \\
\hline 12 & $z$ & 0 & 0.0028 & 0.0020 \\
\hline 13 & albedo & 0 & 0.0013 & 0.0009 \\
\hline
\end{tabular}

$\left(q_{0}\right)$, the parameters $\left(F_{\text {wpmax }}, F_{\text {wpmin }}\right)$ of the water factor $\left(f_{\mathrm{W}}\right)$ and for the parameters influencing processes affecting soil moisture in the top layer; processes that led to increased soil moisture in the top layer also led to increased evaporation from the soil surface and to a diminution in plant-available water.

\section{Intra-annual sensitivity (with variable LAI)}

When LAI variability was incorporated into the sensitivity analysis the sensitivity results changed little except for the delayed onset of the importance of the water factor parameters ( $F_{\text {wpmax }}$ and $\left.F_{\text {wpmin }}\right)$, maximum plant-available water $\left(Q_{\max }\right.$ and $Q 1_{\text {max }}$ ), water-use efficiency $\left(q_{0}\right)$, canopy storage of precipitation ( $z$ ) and surface heat flux (albedo) by days 21-23 days in the driest part of the dry year, and LAI variability shortened the duration of this importance by 10 days, or lengthened it by 39 days in the case of $D_{\max }$ and $D_{\min }$ (Fig. 4).

\section{Discussion}

The application of a simple model framework to a Eucalyptus forest flux site over wet and dry years allowed us to identify the processes that became important as determinants of productivity when site moisture declined, on both inter-annual and intraannual timeframes. Insights have emerged from both the model parameterisation approach and the sensitivity analysis. We discuss these methods and insights below.

\section{Parameterisation}

The simple model defined a minimal set of assumptions about the forest ecosystem, and about the processes that might be active in that system. It also influenced how we used the data; we used the available dataset in two ways: first to estimate the model parameter values or their ranges and second to investigate whether or not processes incorporated in the simple model had relevance to the site. In particular, we assessed whether there were any moisture-related effects on productivity at this site or whether they were negligible owing to access to deep available water sources. The simple framework has made this approach very transparent.

We found that variations in atmospheric and soil water content probably play a significant part in the carbon and water dynamics of this Eucalyptus forest. We found a negative correlation between $F_{\mathrm{c}} / \mathrm{TDR}$ and $\mathrm{D}$ for $\mathrm{D}>1 \mathrm{kPa}$, even when soil moisture was adequate. Parameters were set so that the model would simulate this effect of $\mathrm{D}$ on $F_{\mathrm{c}}$ with reasonable accuracy, and so it would be included in the sensitivity analysis. $F_{\mathrm{c}}$ plotted against soil moisture revealed the possibility that a soil-moisture effect was active at this site. Analysis of the normalised soil water extraction rates (divided by $\mathrm{D}$ ) during drying cycles also supported this possibility (Fig. 2b). From this evidence, we concluded that there were probably soil-moisture effects on productivity, and we parameterised the model to reflect this, and so it would be included in the sensitivity analysis.

There were three indicators of plant-available water in the model. Plant-available water in the $0-0.15 \mathrm{~m}(Q 1)$ and $0-1.20 \mathrm{~m}$ $(Q 2)$ soil layers were two of these indicators used in comparisons with their corresponding measurements to estimate parameters related to the site water balance. The third indicator in the model was the overall plant-available water $(Q)$, which we could only estimate indirectly because there were no measurements of soil water below a depth of $1.20 \mathrm{~m}$. However, to obtain reasonable simulations of all four variables, $Q 1, Q 2, F_{\mathrm{w}}$ and $F_{\mathrm{c}}$, particularly in the dry year, we needed to increase the maximum plant-available water $\left(Q_{\max }\right)$ to a level well above the maximum for the $0-1.20 \mathrm{~m}$ soil layer $\left(Q 2_{\max }\right)$. Thus, we gained confidence in the estimate of $Q_{\max }$ because it was the result of using multiple constraints to inform the model. This is consistent with Leuning et al. (2005), who hypothesised that the tall Eucalyptus trees must have access to deep sources of water to explain similar annual water flux in wet and dry years. It is also consistent with our calculations of water output exceeding water input on a weekly basis, using the measured records of precipitation and soil water content.

The cumulative water and $\mathrm{CO}_{2}$ fluxes in the Fig. $1 b, c$ insets, respectively, clearly show that simulated $\mathrm{CO}_{2}$ flux was reduced in the dry year, even though water flux was similar in both wet and dry years. Although water was available to the plant throughout 

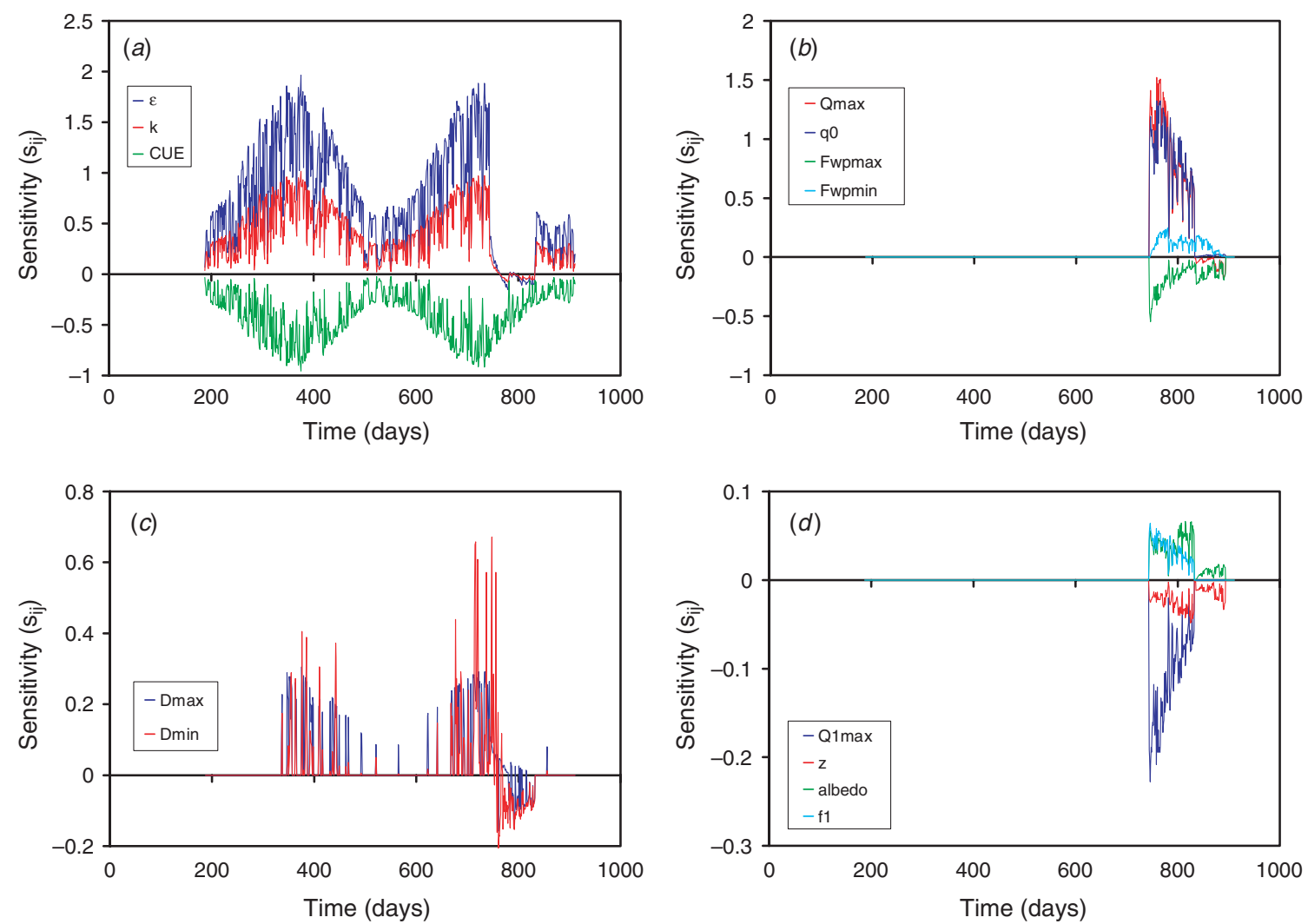

Fig. 3. Daily sensitivity $\left(s_{\mathrm{ij}}\right)$ of simulated productivity (net primary productivity (NPP) or gross primary productivity (GPP) in the case of carbon-use efficiency (CUE)) to small changes in the 13 parameter values listed in Table 4 using a constant leaf area index.

the driest period, low soil and atmospheric moisture content acted to reduce simulated NPP. These dry conditions reduced $f_{\mathrm{D}}$ and $f_{\mathrm{W}}$ (Eqn 3), which led to a reduction in NPP (in Eqn 16), simulating reduced whole-tree conductance to water and stomatal conductance to $\mathrm{CO}_{2}$, but higher $\mathrm{D}$ in the dry year offset reduced whole-tree conductance and led to the annual water flux in the dry year being similar to that in the wet year. This phenomenon has also been found for trees in seasonally dry savanna in north Australia (O'Grady et al. 1999) and for forests in Panama (Meinzer et al. 1999), which were able to exploit progressively deeper sources of soil water during the dry season and maintain constant and even increased rates of water use.

The discrepancy between the modelled and measured $Q 1$ may, in part, reflect a buffering effect in the measured $Q 1$ because of connections with moisture in the deeper adjacent soil layer. Simulated $Q 1$ reflects water dynamics in the top soil layer like a 'bucket' that is isolated from the adjacent layers and, therefore, reflects infiltration into the top layer from precipitation events minus simulated water use extracted from the top layer. Measurements of soil moisture in the top layer were, however, taken with a probe at a depth of $0.15 \mathrm{~m}$ (Zegelin and White 1989; Leuning et al.2005) and may reflect moisture levels influenced by moisture movement between layers in addition to inputs from infiltration and outputs associated with transpiration and soil surface evaporation. Hydraulic lift (Caldwell and Richards 1989; Caldwell et al. 1998; Jackson et al. 2000) is also possible and may help to explain the major discrepancy observed between the measured and modelled soil moisture levels in the $0-1.20 \mathrm{~m}$ soil layer in the weeks after day 786 in Fig. $1 a$.

\section{Sensitivity analysis}

The inter-annual sensitivity results indicated that modelled productivity, NPP or GPP was most sensitive to maximum light-use efficiency $(\varepsilon)$, light-extinction coefficient $(k)$ or CUE, respectively. These three parameters played an important role in both wet and dry years, albeit a diminished role in the dry year (Table 4). The intra-annual sensitivity showed that the $\varepsilon$ and $k$ parameters were important in both years, except during a relatively narrow period of time when soil moisture levels were lowest. The parameter $k$ relates to canopy light absorption and $\varepsilon$ relates to the conversion of absorbed light into plant productivity. Thus, the forest's capacities to absorb light and to convert it into production were very important in both wet and dry years, except during the period with lowest soil moisture availability, which occurred in the second half of the growing season (early autumn) in the dry year. During this relatively narrow period of time, the importance of maximum plant-available water $\left(Q_{\max }\right)$ and water-use efficiency $\left(q_{0}\right)$ increased because $Q_{\max }$ determines the amount of stored water available and $q_{0}$ affects water use (or water saved) and, thus, they both affect the amount of water available to the forest to function 

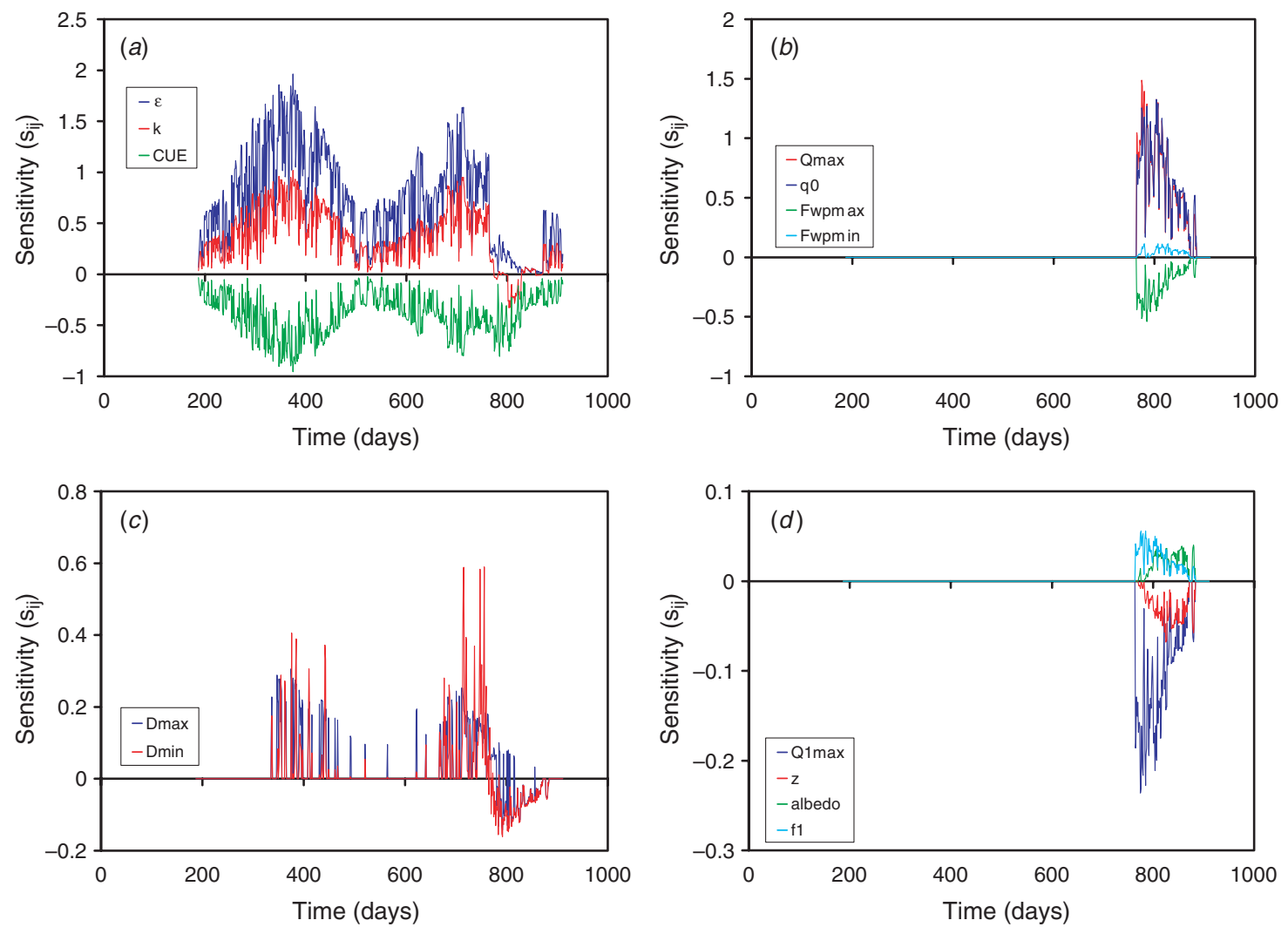

Fig. 4. Daily sensitivity $\left(s_{\mathrm{ij}}\right)$ of simulated productivity (net primary productivity (NPP) or gross primary productivity (GPP) in the case of carbon-use efficiency (CUE)) to small changes in the 13 parameter values listed in Table 4 using a variable leaf area index.

through the whole year, including the driest times of the year. When dry times occur during the growing season when production is high, $Q_{\max }$ and $q_{0}$ may become very important to productivity, depending on the level of decline in the fraction of maximum plant-available water $\left(Q / Q_{\max }\right)$ the forest is subjected to. The $F_{\text {wpmax }}$ parameter defining the critical $Q / Q_{\max }$ point at which plant-available water begins to limit productivity (i.e. $f_{\mathrm{W}}<1$ ) is also most important at the driest times. Thus, we conclude that the hydraulic architecture above and below the ground that increases root depth and $Q_{\max }$, uses water conservatively with respect to the accumulation of biomass $\left(q_{0}\right)$ and is less sensitive to the plant-available water fraction (has lower $F_{\text {wpmax }}$ ) will equip the forest to minimise the loss of productivity arising from dry periods.

In the dry year, variability in LAI tended to decrease the sensitivity of productivity to important parameters. The variability introduced into LAI resulted in an overall reduction in LAI. This LAI reduction tended to reduce the sensitivity of NPP to the light-related ( $\varepsilon$ and $k)$ and the water-related $\left(q_{0}\right.$, $Q_{\text {max }}$ and $Q 1_{\text {max }}, F_{\text {wpmax }}$ and $F_{\text {wpmin }}, D_{\max }$ and $\left.D_{\min }\right)$ parameters in the dry year. Reduction in LAI affects light extinction through the canopy and thus APAR, and its conversion to productivity $(\varepsilon)$. This LAI reduction had less of an impact on $F_{\mathrm{w}}$, particularly when the maximum plant-available water was allowed to exceed the maximum plant-available water in the first $1.20 \mathrm{~m}$ (i.e. $Q_{\max }>Q 2_{\max }$ ). This is consistent with leaf area reduction experiments that have very little effect on sapflow (or transpiration) until large leaf area reductions (up to 50\%) have been made (Pataki et al. 1998; Oren et al. 1999), owing to stomatal compensation in the remaining leaves.

This analysis has provided some insights into the mechanisms linking productivity and site water status (Calder 1992; Honeysett et al. 1992, 1996; Eamus 2003; Rascher et al. 2004; Whitehead and Beadle 2004). The response of stomatal conductance to variation in vapour-pressure deficit and soil water content (Pereira et al. 1987; White et al. 1996; Thomas and Eamus 1999) was simulated through the multiplicative effect of $f_{\mathrm{W}}$ and $f_{\mathrm{D}}$. The effect of vapour pressure $\left(f_{\mathrm{D}}\right)$ was important during the middle and second half of the growing seasons in both wet and dry years, but it overlapped with the effect of soil water $\left(f_{\mathrm{W}}\right)$ to produce a stronger multiplicative effect in the dry year until the soil water effect dominated in the driest part of the dry year (Fig. 3b,c). The stronger multiplicative effect is consistent with stomatal conductance becoming more sensitive to $\mathrm{D}$ with increasing drought, as has been observed previously (Thomas and Eamus 1999). The allocation of biomass to roots and leaves ( $\mathrm{Li}$ and Wang 2003) was represented by maximum soil water availability $\left(Q_{\max }\right)$. This was the most important parameter through the driest months of the dry year. Hydraulic conductance (White et al. 1998; Eamus et al. 2001) in the ecosystem may limit water flow along the soil-plant-atmosphere pathway. Transpiration is a function of hydraulic conductance and is driven by osmotic gradients, including D. To prevent a large decline in leaf water potential 
and to prevent stomatal closure and even xylem embolism, hydraulic conductance must be sufficient to supply adequate water to the leaves. The effect of soil water content $\left(f_{\mathrm{W}}\right)$, in part, represents a reduction in hydraulic conductance in the soil-plant pathway. This effect on productivity became very important in the driest part of the dry year (Fig. 3b). The mechanism of a direct change in canopy leaf area or in specific leaf area that leads to a change in leaf area (Whitehead and Beadle 2004) was represented by the introduction of variation in LAI. On an inter-annual timeframe the overall reduction in LAI reduced the sensitivity of productivity to all 13 parameters. This effectively increased the contrast between wet and dry years with respect to the forest's capacities to absorb light $(k)$ and to convert it into production $(\varepsilon)$. However, it reduced the importance of the moisture-related parameters under dry conditions. Thus, the mechanism of an adjustment in the LAI had a widespread effect, exacerbating the effect of the dry-year conditions on the light-related processes and alleviated the effect on the moisture-related processes compared with the wet year.

Lastly, on mechanisms linking productivity and site water, we attempted to represent variation in RE (Turnbull et al. 2001; Ciais et al. 2005) through the CUE parameter. Productivity (GPP) was consistently very sensitive to this parameter in both the wet and dry years and thus provided limited insight. An alternative representation of this last mechanism might be through light-use efficiency (Eqn 3). For example, under dry conditions with low humidity, where $f_{\mathrm{W}}$ and $f_{\mathrm{D}}$ were $<1$, light-use efficiency would decrease, leading to a decreased conversion of absorbed light into productivity. This effectively simulates an increase in autotrophic respiration under dry conditions. The sensitivity of productivity to $\varepsilon$ and to the parameters associated with $f_{\mathrm{W}}$ and $f_{\mathrm{D}}$ is difficult to evaluate from this analysis. Even if we only consider $\varepsilon$ and the parameters associated with $f_{\mathrm{W}}$, the importance of $\varepsilon$ decreases under dry conditions and the importance of the parameters associated with $f_{\mathrm{W}}\left(Q_{\max }, F_{\text {wpmax }}\right.$ and $\left.F_{\text {wpmin }}\right)$ increase. However, because NPP was insensitive to the parameters associated with $f_{\mathrm{W}}$ in the wet year (Table 4), but was sensitive in the dry year, we could infer that the $\varepsilon f_{\mathrm{W}}$ combination or the combined parameter set $\left(\varepsilon, Q_{\max }, F_{\text {wpmax }}\right.$ and $\left.F_{\text {wpmin }}\right)$ was more important in the dry year. This would imply that respiration (increased under dry conditions; Turnbull et al. 2001; cf. Ciais et al. 2005) could be a mechanism linking productivity and site water status at the study site, but this remains inconclusive from this analysis.

We assumed that CUE was constant in the model, and that GPP was proportional to NPP over the wet and dry years, to represent autotrophic respiration in a simple way, which is supported by empirical results at other sites and by modelling analyses (Gifford 1992, 2003; Dewar et al. 1998, 1999; Waring et al. 1998; DeLucia et al. 2007). However, there is also evidence that CUE can be higher in young trees and possibly under conditions of abundant nutrients or water (e.g. Mäkelä and Valentine 2001; DeLucia et al. 2007; Keeling and Phillips 2007). Therefore, incorporating autotrophic respiration into the model so that it varies with moisture availability appropriately could advance the analyses undertaken in the present study.

The $\delta^{\mathrm{msqr}}$ values presented in Table 4 allow a robust comparison of the same parameters between wet and dry years. However, the ranking between different parameters is less robust because of the protocol of varying each parameter value by $20 \%$ rather than by a small fraction of an accurate range of uncertainty, which is likely to vary considerably across the parameter set even for this simple model (Brun et al. 2001). Nevertheless, the $\delta^{\mathrm{msqr}}$ values do provide some measure of the importance of the different parameters, particularly the further apart they are ranked. For example, the top four parameters in Table 4 could be of similar importance, but compared with the last four parameters in Table 4 they would be considered to be more important. The same problem arises if one attempts to compare the difference between wet and dry years across different parameters. For instance, $Q_{\max }$ and $q_{0}$ are much more sensitive in the dry year, and $F_{\text {wpmax }}$ and $F_{\text {wpmin }}$ are also much more sensitive in the dry year (Table 4), but it is more difficult to say whether an increase in the first pair is more important than an increase in the second pair. A graphical representation of daily sensitivity may provide a better view to judge the relative importance of different parameters and their related processes across wet and dry years. Although such a comparison between parameters will not be truly robust either, it is qualitatively useful.

\section{Conclusions}

A simple ecosystem model can provide a mechanistic explanation for lower annual $\mathrm{CO}_{2}$ uptake in a dry year compared with a wet year, even when annual water flux is similar in the 2 years. The effect of lower soil moisture content presumably leading to reduced canopy conductance and lower $\mathrm{CO}_{2}$ uptake in the dry year was offset by higher vapour-pressure deficits driving water use in the dry year. Consequently, water use in the dry year was similar to water use in the wet year. The hydraulic architecture of the trees (both above and below the ground) at the study site was very important for productivity in the dry year. For instance, plant-available water and, thus, adequate root depth was an important determinant of $\mathrm{CO}_{2}$ uptake at this site in the dry year, specifically during the driest months of the dry year. Above the ground, water-use efficiency was also very important in these months. The effect of vapour-pressure deficit on productivity was important in both the wet and dry years during the middle and second half of the growing season, but not during the driest months of the dry year. Low intrinsic sensitivity (lower $F_{\text {wpmax }}$ ) to the plant-available water fraction $Q / Q_{\max }$ benefited productivity through the driest months. The stomatal responses to vapourpressure deficit and soil water content and hydraulic conductance were important during the dry year, but plant-available water $Q_{\max }$ and water-use efficiency were most important during the driest months of the study period.

\section{Acknowledgements}

D. A. Pepper, R. E. McMurtrie and B. E. Medlyn acknowledge financial support from the Australian Research Council and the Australian Government Department of Climate Change. We are grateful to Ray Leuning and Steve Zegelin at CSIRO, Australia, for the provision of soil moisture and flux data. We are grateful for support provided by TERACC (NSF Grant No. 0090238) for a modelling workshop held in Cronulla, Sydney, Australia, in 2006. 


\section{References}

Brun R, Reichert P, Künsch HR (2001) Practical identifiability analysis of large environmental simulation models. Water Resources Research 37, 1015-1030. doi: 10.1029/2000WR900350

Calder IR (1992) A model of transpiration and growth of Eucalyptus plantation in water limited conditions. Journal of Hydrology (Amsterdam) 130, 1-15.

Caldwell MM, Richards JH (1989) Hydraulic lift: water efflux from upper roots improves effectiveness of water uptake by deep roots. Oecologia 79, 1-5. doi: 10.1007/BF00378231

Caldwell MM, Dawson TE, Richards JH (1998) Hydraulic lift: consequences of water efflux from the roots of plants. Oecologia 113, 151-161. doi: $10.1007 / \mathrm{s} 004420050363$

Ciais Ph, Reichstein M, Viovy N, Granier A, Ogée J et al. (2005) Europe-wide reduction in primary productivity caused by the heat and drought in 2003 . Nature 437, 529-533. doi: 10.1038/nature03972

Comins HN, McMurtrie RE (1993) Long-term response of nutrient-limited forests to $\mathrm{CO}_{2}$-enrichment: equilibrium behaviour of plant-soil models. Ecological Applications 3, 666-681. doi: 10.2307/1942099

Corbeels M, McMurtrie RE, Pepper DA, O'Connell AM (2005) A processbased model of nitrogen cycling in forest plantations Part II. Simulating growth and nitrogen mineralisation of Eucalyptus globulus plantations in south-western Australia. Ecological Modelling 187, 449-474. doi: 10.1016/j.ecolmodel.2005.07.004

CSIRO and Australian Bureau of Meteorology (2007) 'Climate change in Australia: technical report 2007.' (CSIRO: Collingwood)

Davidson NJ, Reid JB (1989) Response of eucalypt species to drought. Australian Journal of Ecology 14, 139-156. doi: 10.1111/j.14429993.1989.tb01423.x

DeLucia EH, Drake JE, Thomas RB, Gonzalez-Meler M (2007) Forest carbon use efficiency: is respiration a constant fraction of gross primary production? Global Change Biology 13, 1157-1167. doi: 10.1111/ j.1365-2486.2007.01365.x

Dewar R (1997) A simple model of light and water use evaluated for Pinus radiata. Tree Physiology 17, 259-265.

Dewar RC, Medlyn BE, McMurtrie RE (1998) A mechanistic analysis of light and carbon use efficiencies. Plant, Cell \& Environment 21, 573-588. doi: 10.1046/j.1365-3040.1998.00311.x

Dewar RC, Medlyn BE, McMurtrie RE (1999) Acclimation of the respiration photosynthesis ratio to temperature: insights from a model. Global Change Biology 5, 615-622. doi: 10.1046/j.1365-2486.1999. 00253.x

Dye PJ, Jacobs S, Drew D (2004) Verification of 3-PG growth and water-use predictions in twelve Eucalyptus plantation stands in Zululand, South Africa. Forest Ecology and Management 193, 197-218. doi: 10.1016/j. foreco.2004.01.030

Eamus D (2003) How does ecosystem water balance affect net primary productivity of woody ecosystems? Functional Plant Biology 30, 187-205. doi: 10.1071/FP02084

Eamus D, Hutley LB, O'Grady AP (2001) Daily and seasonal patterns of carbon and water fluxes above a north Australian savanna. Tree Physiology 21, 977-988.

Eliasson PE, McMurtrie RE, Pepper DA, Strömgren M, Linder S, Ågren GI (2005) The response of heterotrophic $\mathrm{CO}_{2}$-flux to soil warming. Global Change Biology 11, 167-181. doi: 10.1111/j.1365-2486.2004. 00878.x

Fitzpatrick EA, Nix HA (1970) The climatic factor in Australian grassland ecology. In 'Australian Grasslands.' (Ed. RM Moore) pp. 2-26. (Australian National University Press: Canberra)

Fuchs EE, Livingston NJ (1996) Hydraulic control of stomatal conductance in Douglas-fir [Pseudotsuga menziesii (Mirb.) Franco] and alder [Alnus rubra (Bong.)] seedlings. Plant, Cell \& Environment 19, 1091-1098. doi: 10.1111/j.1365-3040.1996. tb00216.x
Gifford RM (1992) Interaction of carbon dioxide with growth-limiting environmental factors in vegetation productivity: implications for the global carbon cycle. Advances in Bioclimatology 1, 24-58.

Gifford RM (2003) Plant respiration in productivity models: conceptualisation, representation and issues for global terrestrial carbon-cycle research. Functional Plant Biology 30, 171-186. doi: 10.1071/FP02083

Hanson PJ, Amthor JS, Wullschleger SD, Wilson KB, Grant RF et al. (2004) Oak forest carbon and water simulations: model intercomparisons and evaluations against independent data. Ecological Monographs 74, 443-489. doi: 10.1890/03-4049

Honeysett JL, Beadle CL, Turnbull CRA (1992) Evapotranspiration and growth of two contrasting species of eucalypts under non-limiting and limiting water availability. Forest Ecology and Management 50, 203-216. doi: 10.1016/0378-1127(92)90336-8

Honeysett JL, White DA, Worledge D, Beadle CL (1996) Growth and water use of Eucalyptus globulus and E. nitens in irrigated and rainfed plantations. Australian Forestry 59, 64-73.

Hughes L (2003) Climate change and Australia: trends, projections and impacts. Austral Ecology 28, 423-443. doi: 10.1046/j.1442-9993.2003. 01300.x

Jackson RB, Sperry JS, Dawson TE (2000) Root water uptake and transport: using physiological processes in global predictions. Trends in Plant Science 5, 482-488. doi: 10.1016/S1360-1385(00)01766-0

Keeling HC, Phillips OL (2007) The global relationship between forest productivity and biomass. Global Ecology and Biogeography 16, 618-631. doi: 10.1111/j.1466-8238.2007.00314.x

Kirschbaum MUF, Keith H, Leuning R, Cleugh HA, Jacobsen KL, van Gorsel E, Raison RJ (2007) Modelling net ecosystem carbon and water exchange of a temperate Eucalyptus delegatensis forest using multiple constraints. Agricultural and Forest Meteorology 145, 48-68. doi: 10.1016/j.agrformet.2007.04.002

Ladiges PY (1974) Variations in drought tolerance in Eucalyptus viminalis Labill. Australian Journal of Botany 22, 489-500. doi: 10.1071/ BT9740489

Lavery B, Joung G, Nicholls N (1997) An extended high-quality historical rainfall dataset for Australia. Australian Meteorological Magazine 46, 27-38.

Leuning R, Cleugh HA, Zegelin SJ, Hughes D (2005) Carbon and water fluxes over temperate Eucalyptus forest and tropical wet/dry savanna in Australia: measurements and comparison with MODIS remote sensing estimates. Agricultural and Forest Meteorology 129, 151-173. doi: 10.1016/j.agrformet.2004.12.004

Li CY, Wang KY (2003) Differences in drought responses of three contrasting Eucalyptus microtheca F. Muell. populations. Forest Ecology and Management 179, 377-385. doi: 10.1016/S0378-1127(02)00552-2

Mäkelä A, Valentine HT (2001) The ratio of NPP to GPP: evidence of change over the course of stand development. Tree Physiology 21, 1015-1030.

McKenzie NJ, Ryan PJ (1999) Spatial prediction of soil properties using environmental correlation. Geoderma 89, 67-94. doi: 10.1016/S00167061(98)00137-2

McMurtrie RE, Rook DA, Kelliher FM (1990) Modelling the yield of Pinus radiata on a site limited by water and nitrogen. Forest Ecology and Management 30, 381-413. doi: 10.1016/0378-1127(90)90150-A

Medlyn BE, Barrett D, Landsberg J, Sands P, Clement R (2003) Conversion of canopy intercepted radiation to photosynthate: review of modelling approaches for regional scales. Functional Plant Biology 30, 153-169. doi: 10.1071/FP02088

Meinzer FC, Andrade JL, Goldstein G, Holbrook NM, Cavelier J, Wright SJ (1999) Partitioning of soil water among canopy trees in a seasonally dry tropical forest. Oecologia 121, 293-301. doi: 10.1007/s004420050931

O'Grady AP, Eamus D, Hutley LB (1999) Transpiration increases during the dry season: patterns of tree water use in eucalypt open-forests of northern Australia. Tree Physiology 19, 591-597. 
Oren R, Phillips N, Ewers BE, Pataki DE, Megonigal JP (1999) Sap-fluxscaled transpiration responses to light, vapour pressure deficit, and leaf area reduction in a flooded Taxodium distichum forest. Tree Physiology 19, 337-347.

Parton WJ, Schimel DS, Cole CV, Ojima DS (1987) Analysis of factors controlling soil organic matter levels in Great Plains grasslands. Soil Science Society of America Journal 51, 1173-1179.

Pataki DE, Oren R, Phillips N (1998) Responses of sap flux and stomatal conductance of Pinus taeda L. to stepwise reductions in leaf area. Journal of Experimental Botany 49, 871-878. doi: 10.1093/jexbot/ 49.322.871

Pepper DA, Eliasson PE, McMurtrie RE, Corbeels M, Ågren GI, Strömgren M, Linder S (2007) Simulated mechanisms of soil N feedback on the forest $\mathrm{CO}_{2}$ response. Global Change Biology 13, 1265-1281. doi: 10.1111/j.1365-2486.2007.01342.x

Pereira JS, Tenhunen JD, Lange OL (1987) Stomatal control of photosynthesis of Eucalyptus globulus Labill. trees under field conditions in Portugal. Journal of Experimental Botany 38, 1678-1688. doi: 10.1093/jxb/ 38.10 .1678

Pittock B (2003) 'Climate change: An Australian guide to the science and potential impacts.' (Commonwealth of Australia: Canberra)

Rascher U, Bobich EG, Lin GH, Walter A, Morris T et al. (2004) Functional diversity of photosynthesis during drought in a model tropical rainforest the contributions of leaf area, photosynthetic electron transport and stomatal conductance to reduction in net ecosystem carbon exchange. Plant, Cell \& Environment 27, 1239-1256. doi: 10.1111/j.1365-3040. 2004.01231.x

Reichert P (2006) A standard interface between simulation programs and systems analysis software. Water Science and Technology 53, 267-275. doi: 10.2166/wst.2006.029

Ritchie JT (1972) Model for predicting evaporation from a row crop with incomplete cover. Water Resources Research 8, 1204-1213. doi: 10.1029/WR008i005p01204

Schulze E-D, Kelliher FM, Körner C, Lloyd J, Leuning R (1994) Relationships among maximum stomatal conductance, ecosystem surface conductance, carbon assimilation rate, and plant nitrogen nutrition: a global scaling exercise. Annual Review of Ecology and Systematics 25, 629-660. doi: 10.1146/annurev.es.25.110194. 003213
Thomas DS, Eamus D (1999) The influence of predawn leaf water potential on stomatal responses to atmospheric water content at constant $\mathrm{C}-\mathrm{i}$ and on stem hydraulic conductance and foliar ABA concentrations. Journal of Experimental Botany 50, 243-251. doi: 10.1093/jexbot/50.331.243

Turnbull MH, Whitehead D, Tissue DT, Schuster WSF, Brown KJ, Griffin KL (2001) Responses of leaf respiration to temperature and leaf characteristics in three deciduous tree species vary with site water availability. Tree Physiology 21, 571-578.

van Gorsel E, Leuning R, Cleugh HA, Keith H, Suni T (2007) Nocturnal carbon efflux: reconciliation of eddy covariance and chamber measurements using an alternative to the $\mathrm{u}^{*}$-threshold filtering technique. Tellus 59B, 397-403.

Waring RH, Landsberg JJ, Williams M (1998) Net primary production of forests: a constant fraction of gross primary production? Tree Physiology 18, 129-134.

White DA, Beadle CL, Worledge D (1996) Leaf water relations of Eucalyptus globulus ssp. globulus and E. nitens: seasonal, drought and species effects. Tree Physiology 16, 469-476.

White DA, Beadle CL, Worledge D, Honeysett JL, Cherry ML (1998) The influence of drought on the relationship between leaf and conducting sapwood area in Eucalyptus globulus and Eucalyptus nitens. Trees (Berlin) 12, 406-414.

Whitehead D, Beadle CL (2004) Physiological regulation of productivity and water use in Eucalyptus: a review. Forest Ecology and Management 193, 113-140. doi: 10.1016/j.foreco.2004.01.026

Zegelin SJ, White I (1989) Improved field probes for soil water content and electrical conductivity measurement using time domain reflectometry. Water Resources Research 25, 2367-2376. doi: 10.1029/ WR025i011p02367

Zhang L, Dawes WR, Walker GR (2001) Response of mean annual evapotranspiration to vegetation changes at catchment scale. Water Resources Research 37, 701-708. doi: 10.1029/2000WR900325

Zhang L, Hickel K, Dawes WR, Chiew FHS, Western AW, Briggs PR 2004) A rational function approach for estimating mean annual evapotranspiration. Water Resources Research 40, W02502. doi: 10.1029/2003WR002710

Manuscript received 14 April 2008, accepted 4 June 2008 